\title{
The JNK-Like MAPK KGB-1 of Caenorhabditis Elegans Promotes Reproduction, Lifespan, and Gene Expressions for Protein Biosynthesis and Germline Homeostasis but Interferes with Hyperosmotic Stress Tolerance
}

\author{
Peter Gerke Alex Keshet Ansgar Mertenskötter Rüdiger J. Paul \\ Institute of Zoophysiology, University of Münster (WWU), Münster, Germany
}

Key Words

Activator protein 1 - Chaperone $\cdot$ FOS - Insulin/IGF receptor ortholog $\cdot$ JUN - Regulatory volume increase $\cdot$ Sperm $\bullet$ Target of rapamycin (TOR)

\begin{abstract}
Aims: This study focused on the role of the JNK-like MAPK (mitogen-activated protein kinase) KGB-1 (kinase, GLH-binding 1) for osmoprotection and other vital functions. Methods: We mapped KGB-1 expression patterns and determined lifespan, reproduction and survival rates as well as changes in body volume, motility, and GPDH (glycerol-3-phosphate dehydrogenase) activity for glycerol production in wildtype (WT), different signaling mutants (including a $\mathrm{kg} b-1$ deletion mutant, $\mathrm{kg} b-1 \Delta$ ) and RNAi-treated worms under control and hyperosmotic conditions. KGB-1-mediated gene expressions were studied, for instance, by RNA Sequencing, with the resulting transcriptome data analyzed using orthology-based approaches. Results: Surprisingly, mutation/RNAi of $\mathrm{kg} b-\mathrm{l}$ and fos- 1 (gene for an AP-1, activator protein 1 , element) significantly promoted hyperosmotic resistance, even though hyperosmotic GPDH activity was higher in WT than in $k g b-1 \Delta$. KGB-1 and moderate hyperosmolarity promoted and severe hyperosmolarity repressed $k g b-1$, fos- 1 , and jun- 1 (gene for another AP-1 element) expression. Transcriptome profiling revealed, for instance, down-regulated genes for protein biosynthesis and up-regulated genes for membrane transporters in $\mathrm{kgb}-1 \Delta$ and up-regulated genes for GPDH-1 or detoxification in WT, with the latter indicating cellular damage and less effective osmoprotection in WT. Conclusion: KGB-1 promotes reproduction and lifespan and fosters gene expressions for AP-1 elements, protein biosynthesis, and balanced gametogenesis, but inhibits expressions for membrane transporters perhaps in order to control energy consumption. Reduced protein biosyntheses and enhanced membrane transports in $\mathrm{kgb}$ $1 \Delta$ most likely contribute to the high hyperosmotic tolerance of the mutant by easing the burden of the existing chaperone machinery and promoting regulatory volume increases upon hyperosmotic stress.

Copyright (c) 2014 S. Karger AG, Basel

Rüdiger J. Paul

Institute of Zoophysiology, University of Münster (WWU),

Schlossplatz 8, D-48143 Münster (Germany)

Tel. +49 25183 23851, Fax +49 25183 23876, E-Mail paulr@uni-muenster.de
\end{abstract}




\section{Cellular Physiology and Biochemistry}

Cell Physiol Biochem 2014;34:1951-1973

\begin{tabular}{l|l}
\hline DOI: $10.1159 / 000366392$ & (C) 2014 S. Karger AG, Basel
\end{tabular}

Gerke et al.: The JNK-Like MAPK KGB-1 of C. Elegans

\section{Introduction}

Like in other animals, C. elegans cells (and the worm itself) lose water and shrink upon hyperosmotic exposure but regain their initial volume within a few tens of minutes [1]. Nevertheless, rapid and extensive protein damage may occur depending on the intensity of the hyperosmotic stress [2]. Later cell homeostasis is achieved in this species by de novo synthesis of glycerol, with GPDH catalyzing its rate-limiting step and accumulated misfolded proteins triggering gpdh-1 expression [3]. Insulin/IGF-like signaling and DAF-16-mediated gene expressions for trehalose synthesis enzymes have also been reported to contribute to osmoprotection in C. elegans [4] such as imports of another compatible osmolyte by the $\mathrm{H}^{+}$-dependent myo-inositol transporter HMIT-1.1 [5]. To minimize protein damage, protein biosynthesis rate may be lowered to reduce the risk of overloading the existing chaperone machinery [6]. As the regulatory pathways for cellular hyperosmotic stress responses are not yet understood in detail [1], we focused on MAPK signaling pathways, which can be considered as ancient transducers of osmosensory signals [7]. Evolution has caused intense variation in their structure and function resulting in MAPK processing of many kinds of signals and MAPK control of various physiological processes. Among the three subgroups of MAPKs, p38 kinases and c-Jun N-terminal kinases (JNK) are frequently involved in stress responses of animal cells [8]. C. elegans expresses JNK and JNK-like MAPKs in a tissuespecific way, with JNK-1 and its upstream kinase, the MAP2K JKK-1, expressed only in neuronal cells $[9,10]$. The signaling pathway of the JNK-like MAPK KGB-1 is composed of MLK-1 (MAP3K), MEK-1 (MAP2K), and KGB-1 [11, 12]. This cascade is controlled by MAX-2 (a Ste20-related kinase activating MLK-1) and MIG-2 (a Rac-type small GTPase activating MAX-2) [13]. The MAPK phosphatase VHP-1 negatively regulates the KGB-1 pathway by dephosphorylating KGB-1 [11, 14], and the scaffold protein SHC-1 binds MLK-1 and MEK-1 to promote the phosphorylation of MEK-1 and later KGB-1 [12]. Perhaps, the SEK-1/PMK1 p38-type MAPK pathway [15] also affects KGB-1 activity [16]. The expression of mek-1 in neurons and of $m l k-1, m e k-1$, and $s h c-1$, for instance, in muscles, hypodermis, intestine, pharynx, and uterine endothelial cells $[12,17,18]$ as well as KGB-1 expression in germ cells (oocytes) [16] indicate important roles of KGB-1 signaling for many different functions. KGB1 has been reported to interact with germline RNA helicases (GLHs 1-4) [16, 19], which are constitutive components of germ cell-specific P granules (aggregates of RNA and proteins) that are required for germ line proliferation, oogenesis, and fertility [20-22]. It was also suggested that KGB-1 and CSN-5 (a subunit of the COP9 signalosome, which regulates protein stability [23]) control germline homeostasis. Mutations of $m l k-1, m e k-1$, and $k g b-1$, on the other hand, caused a reduced tolerance to heavy metals [11, 12,17]. Another study [18] showed a reduced tolerance of shc-1 $\Delta$ to heavy metals, heat, and oxidative stress as well as effects of SHC-1 on DAF-2 (dauer formation 2) signaling [24] resulting in a reduced nuclear localization of DAF-16 in shc-1 $\Delta$. KGB-1 has recently been shown to phosphorylate FOS-1 (a bZIP transcription factor) to derepress heavy metal tolerance genes, which are repressed by unphosphorylated FOS-1 [25]. Further on, positive effects of the Bacillus thuringiensis toxin Cry5B on $\mathrm{kgb}-1$ transcription have been reported, just as a reduced tolerance of $\mathrm{kgb}$ $1 \Delta$ (and mek-1 $\Delta$ ) to Cry5B [26] or Pseudomonas aeruginosa [14]. The underlying KGB-1mediated defense pathway against pore-forming toxins from soil bacteria involves again bZIP transcription factors (JUN-1, FOS-1), which contribute to the forming of AP-1 complexes [27]. KGB-1/AP-1 signaling (i.e., KGB-1-mediated phosphorylation of JUN-1 and FOS-1) also constitutes a fasting-responsive pathway, which promotes longevity through regulating proteostasis (i.e., up-regulation of the SCF E3 ligase complex and activation of the ubiquitin proteasome system to degrade damaged or unused proteins) and collaborating with nuclear DAF-16 [28]. Linked to an age-dependent antagonistic modulation of DAF-16, KGB-1 function changes with age [29], causing stress protection in developing larvae but a lower resistance to heavy metals and protein folding stress in young adults.

After detecting effects of KGB-1 on hyperosmotic tolerance in C. elegans, we studied KGB-1 expression patterns, checked for contributions of KGB-1 and insulin/IGF-like (DAF-2) 


\section{Cellular Physiology and Biochemistry}

Cell Physiol Biochem 2014;34:1951-1973

\begin{tabular}{l|l}
\hline DOI: $10.1159 / 000366392$ & (C) 2014 S. Karger AG, Basel
\end{tabular}

www.karger.com/cpb

Gerke et al.: The JNK-Like MAPK KGB-1 of C. Elegans

signaling to hyperosmotic resistance and its mechanisms, and analyzed effects of KGB-1 and hyperosmolarity on gene expression. Expression patterns were studied using fluorescent protein reporter genes. Indications for an elevated hyperosmotic tolerance of a $\mathrm{kg} b$-1 deletion mutant from studies on reproduction rate and lifespan initiated more detailed investigations of the effects of hyperosmolarity on survival rate, body volume and motility, and the activity of the osmolyte-producing enzyme GPDH as well as on the contributions of DAF-2 signaling to hyperosmotic tolerance. Effects of KGB-1 and hyperosmolarity on gene expressions were studied using RT-PCR, a reporter gene assay, and RNA Sequencing (RNA-Seq; nextgeneration sequencing). This study provides novel insights into inhibitory and activating pathways for cellular hyperosmotic stress responses, the mechanisms of osmoprotection, and the physiological role of the JNK-like MAPK KGB-1.

\section{Materials and methods}

Wildtype and mutant strains

C. elegans N2 (Bristol variety) and mutants, hereinafter referred to as $\mathrm{kgb}-1 \Delta$ [KB3 $\mathrm{kgb}-1$ (um3) IV], jnk-

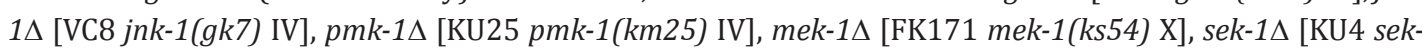

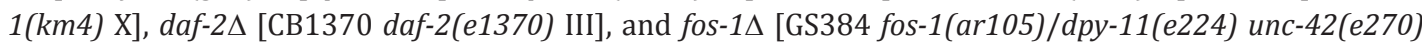
V], were obtained from the Caenorhabditis Genetics Center (CGC; http://www.cbs.umn.edu/CGC/). Worms were kept at $20^{\circ} \mathrm{C}$ on NGM with E.coli OP50 as food source. According to German law, experiments carried out on the invertebrate C. elegans do not have to be announced or approved.

\section{Transgenic strains}

The $P_{k g b-1}:: g f p$ plasmid was constructed by fusion of a nuclear localization signal (NLS) and the GFP coding sequence to a $1.770-\mathrm{kbp}$ genomic fragment upstream of the $\mathrm{kg} b-1$ translational start codon $\left(P_{k g b \text { - }}\right.$ ${ }_{1}^{1}$ ). $P_{k g b-1}$ was amplified from N2 genomic DNA by PCR (Taq-polymerase; Segenetic, Borken, Germany) (primers: 5'-GGTGGGGTGACGATGTGTCG-3', 5'-TTCTGACCCGGGGGCGTTTACCTC-3'), and the associated BamHI/HindIII fragment was cloned into pPD95.67 (Andrew Fire, Stanford, USA). The $k g b-1:: g f p$ plasmid was made by fusion of the GFP coding sequence to a 1.770-kbp genomic fragment upstream of the $\mathrm{kg} b$ 1 translational start codon $\left(P_{k g b-1}\right)$ and the KGB-1 coding sequence without the last two N-terminal codons. The cDNA of $k g b-1$ was amplified by PCR (primers: 5'-AGTGGATCCGCCGGTACATAACGA-3', 5'-TTGGTACCCCAGTGAAAATGTCGTGGTCGG-3') and cloned into pJET1/blunt (GeneJET ${ }^{\mathrm{TM}}$ PCR Cloning Kit, Fermentas, St. Leon-Rot, Germany). BamHI/KpnI digestion enabled cloning of the $\mathrm{kg} b$ - 1 fragment (1.157 $\mathrm{kbp}$ ) into the $P_{k g b-1}:: g f p$ plasmid (between $\mathrm{P}_{k g b-1}$ and $g f p$ without NLS signal). The $P_{f o s-1}:$ :ecfp plasmid was constructed by fusion of the ECFP (enhanced cyan fluorescent protein) coding sequence to a 5.942-kbp genomic fragment upstream of the fos- $1 b$ translational start codon to cover at best both $f o s-1 b$ and fos- $1 a$ promoters [30]. $P_{\text {fos }-1}$ was amplified from N2 genomic DNA by PCR (Phusion ${ }^{\circledR}$ DNA polymerase; Finnzymes, Vantaa, Finland), inserting with it a 5'-KpnI restriction site (primers: 5'-GGTACCATTTTTGCATGTTT-3', 5'-TCCTCGCCCTTGCTCACCATTCCACTCTCTTATATAGCAG-3'). ecfp was amplified from the pCAG-CFP plasmid (Addgene, Cambridge, MA, USA) by PCR, inserting with it a $3^{\prime}$-BamHI restriction site (primers: 5'-CTGCTATATAAGAGAGTGGAATGGTGAGCAAGGGCGAGGA-3', 5'-GGATCCTTACTTGTACAGCTCGTCCA-3'). Both PCR products $\left(P_{f o s-1}, e c f p\right)$ were fused and amplified by PCR (primers: 5'-GGTACCATTTTTGCATGTTT-3', 5'-GGATCCTTACTTGTACAGCTCGTCCA-3') and cloned into pJET1.2/blunt. All plasmids were checked by sequencing.

The reporter strains $P_{k g b-1}:: g f p$ (MS10), $k g b-1:: g f p$ (MS11), and $P_{f o s-1}:: e c f p$ (MS12) were generated by injecting the corresponding plasmids at a concentration of $200 \mathrm{ng} / \mu \mathrm{L}\left(P_{k g b-1}:: g f p\right), 100 \mathrm{ng} / \mu \mathrm{L}\left(P_{f o s-1}:: e c f p\right)$, or $50 \mathrm{ng} / \mu \mathrm{L}(\mathrm{kgb}-1:: g f p)$ into wildtype (N2 Bristol), along with the plasmid pRF4 [100 ng/ $\mu \mathrm{L}$ [31], which carried the co-injection marker rol-6(su1006) [32]. The transgenic strain TJ356 carrying $P_{d a f-16}-d a f-16:: g f p$ was obtained from the Caenorhabditis Genetics Center (CGC; http://www.cbs.umn.edu/CGC/).

RNA interference

For RNA interference (gene knock-down), double-stranded RNA was applied by feeding the E. coli HT115 strains provided by Source BioScience LifeSciences (Nottingham, UK): kgb-1-RNAi [T07A9.3], sek- 


\section{Cellular Physiology and Biochemistry}

Cell Physiol Biochem 2014;34:1951-1973

\begin{tabular}{l|l}
\hline DOI: $10.1159 / 000366392$ & (c) 2014 S. Karger AG, Basel
\end{tabular}

www.karger.com/cpb

Gerke et al.: The JNK-Like MAPK KGB-1 of C. Elegans

1-RNAi [R03G5.2], daf-16-RNAi [R13H8.1], fos-1-RNAi [F29G9.4], and ctrl-RNAi (L4440, control, empty vector). Identity of bacteria was checked by PCR. Bacteria were grown at $37^{\circ} \mathrm{C}$ for 18 hours in $2 \mathrm{xYT}+\mathrm{Amp}$ medium [33]. NGM plates ( $1 \mathrm{mmol} / \mathrm{L}$ isopropyl $\beta$-D-1-thiogalactopyranoside, IPTG; $100 \mu \mathrm{g} / \mathrm{mL}$ ampicillin) were seeded with $750 \mu \mathrm{L}$ bacterial suspension (HT115) and allowed to grow for 24 hours at $20^{\circ} \mathrm{C}$ to induce dsRNA expression. Synchronized L1 larvae were seeded to these plates, grown until the (young) adult stage, and then submitted to hyperosmotic test conditions on NGM plates inoculated with the respective bacterial strain.

\section{Microscopy}

An Axiovert 100 (Zeiss, Germany), equipped with a Kappa CF 8/1 FMC CCD (Kappa optronics, Gleichen, Germany), Nikon COOLPIX 990 or Canon EOS 350D camera, was used for the fluorescence microscopy of worms, which were anesthetized with $10 \mathrm{mM}$ Levamisole in M9 buffer. Image processing was done using Adobe Photoshop $^{\oplus}$ (Adobe Systems Incorporated, San Jose, CA, USA) or ImageJ (v. 1.44; http://imagej.nih. gov/ij/). To evaluate fos-1 expression (Fig. 6F, G), pictures of worms were taken at identical camera settings. With ImageJ, the RGB channels of a picture were splitted, and the red channel was subtracted from the blue channel. After contrast enhancement (at identical settings), the mean pixel intensity of the two posterior intestinal segments was determined. The results were normalized with respect to mean pixel intensities from control animals.

\section{Experimental protocol I: Reproduction and lifespan of worms}

To determine reproduction and lifespan, single synchronized L1 larvae were transferred to control (standard $\mathrm{NaCl}$ concentration, $51 \mathrm{mmol} / \mathrm{L}$ ) or test (standard $\mathrm{NaCl}$ concentration plus $200 \mathrm{mmol} / \mathrm{L} \mathrm{NaCl}$ ) plates (NGM plates, seeded with E. coli OP50), and transferred every 24 hours to fresh plates to avoid mixing with offspring. Lifespan was counted from the date of bleaching worms [34]. The number of offspring per day as well as lifespan were monitored for each worm. Survival was tested by applying gentle touch stimuli. Worms leaving NGM and dying at the wall were excluded from evaluation.

Experimental protocol II: Motility and survival of worms

Synchronized (young) adult worms were transferred to control or test (standard $\mathrm{NaCl}$ concentration plus $100-700 \mathrm{mmol} / \mathrm{L} \mathrm{NaCl}$ ) plates (NGM plates, seeded with E. coli OP50 or E. coli HT115 expressing dsRNA), and transient (motility) or permanent immobility (survival) was tested at different points in time by applying gentle touch stimuli.

\section{Experimental protocol III: Changes in body volume}

Single synchronized (young) adult worms were incubated for 24 hours in wells of 24-well microtitre plates, containing standard NGM medium plus $400 \mathrm{mmol} / \mathrm{L} \mathrm{NaCl}$ as well as $10 \mu \mathrm{L}$ E. coli OP50 suspension. Using a microscope and camcorder, short image sequences were taken from each worm, before (control, $0 \mathrm{~h}$ ) and after transferring worms to the hyperosmotic condition (5, 20, and $60 \mathrm{~min}, 4$ and $24 \mathrm{~h}$ ). Image was used for image processing. One picture of each sequence was selected and converted to 8-bit gray scale, followed by background subtraction and threshold implementation. Then, the area of the worm was evaluated. Percentage changes in area (body volume) were calculated by normalizing with respect to the area under control conditions $(0 \mathrm{~h})$.

\section{Experimental protocol IV: DAF-16 translocation assay}

Synchronized (young) adult worms of the TJ356 strain were incubated for 24 hours on control or test (standard $\mathrm{NaCl}$ concentration plus 200-700 mmol/L NaCl) plates (NGM plates, seeded with E. coli OP50 or E. coli HT115 expressing dsRNA). A final heat stress $\left(37^{\circ} \mathrm{C}, 1 \mathrm{~h}\right)$ was applied in a heating cabinet to check for proper DAF-16 nuclear translocation. After hyperosmotic (or heat) incubation, fluorescence images of randomly chosen worms were taken, and the percentage of worms showing only cytoplasmic localization of DAF-16::GFP determined.

\section{RNA-Seq analysis}

Synchronized (young) adult worms, WT and $\mathrm{kg} b-1 \Delta$, from six different cultures each were incubated for $3 \mathrm{~h}$ under control and/or test (standard $\mathrm{NaCl}$ concentration plus $400 \mathrm{mmol} / \mathrm{L} \mathrm{NaCl}$ ) conditions $\left(20^{\circ} \mathrm{C}\right)$ 


\section{Cellular Physiology and Biochemistry}

Cell Physiol Biochem 2014;34:1951-1973

\begin{tabular}{l|l}
\hline DOI: $10.1159 / 000366392$ & (c) 2014 S. Karger AG, Basel
\end{tabular}

www.karger.com/cpb

Gerke et al.: The JNK-Like MAPK KGB-1 of C. Elegans

on NGM plates, seeded with E. coli OP50 (per condition and strain, two plates containing several hundred worms each). After incubation, animals were washed off the plates with sterile water of corresponding $\mathrm{NaCl}$ molarity (washing medium). After washing them two times with $1 \mathrm{ml}$ washing medium to get rid of feeding bacteria, and adding RNAiso-G (Segenetic, Borken, Germany), they were frozen in liquid nitrogen. After a multiple thermal disruption of worms (liquid nitrogen, $35^{\circ} \mathrm{C}$ ), chloroform extraction on ice $(10 \mathrm{~min})$, and centrifugation $\left(12,000 \times \mathrm{g}, 4^{\circ} \mathrm{C}, 15 \mathrm{~min}\right)$, RNA was isolated using RNase-free DNase sets and RNeasy ${ }^{\circledR}$ mini kits (Qiagen, Hilden, Germany). In addition, several provisions were made to work under RNase-free conditions. Quality control was carried out with an Agilent Bioanalyzer ${ }^{\circledR}$ (Agilent Technologies, Böblingen, Germany). After adding RNAstable ${ }^{\mathrm{TM}}$ matrix (Biomatrica, San Diego, CA, USA), and vacuum centrifugation for drying ( $2 \mathrm{~h}$ ), samples were sent to the Beijing Genomics Institute (BGI) for RNA-Seq analysis by Illumina HiSeq2000 technology. Briefly, mRNA was purified using oligo-(dT)-magnetic beads, and first and second strand cDNA-synthesis was carried out using random hexamer-primers. After ligation with sequencing adaptors, samples were sequenced with Illumina HiSeq2000 with minimally 10 Megareads and a sequencing quality of more than $98 \%$ clean reads. Reads were mapped to Wormbase release WS223. Gene expression was calculated with the RPKM-method (Reads Per Kb per Million reads) out of the number of reads for one gene, the transcript length, and the overall number of reads in the sample [35]. The $P$-value from differential gene expression tests [36] specifies the probability of a gene equally or unequally expressed between two samples, and the False Discovery Rate (FDR) is a method to determine the threshold of $P$-values in multiple tests. In accordance with the proposals of BGI, we took a FDR $<0.005$ as threshold for differentially expressed genes.

\section{Semi-quantitative RT-PCR}

Synchronized (young) adult worms of wildtype and $\mathrm{kgb}-1 \Delta$ were washed off from control plates with washing medium (sterile water plus $51 \mathrm{mmol} / \mathrm{L} \mathrm{NaCl}$ ) and transferred to test (standard $\mathrm{NaCl}$ concentration plus 200, 300, or $400 \mathrm{mmol} / \mathrm{L} \mathrm{NaCl}$ ) plates (NGM plates, seeded with E. coli OP50). After incubation, worms were washed off and cleaned several times with washing medium to exclude bacteria. RNA was isolated using RNAiso-G. After reverse transcription of $1 \mu \mathrm{g}$ total RNA per sample using oligo(dT) ${ }_{18}$ primers (First Strand cDNA Synthesis Kit; Fermentas, St. Leon-Rot, Germany), $1 \mu \mathrm{l}$ cDNA was used for semiquantitative RT-PCR. Using $c d c-42$ as housekeeping gene [37] (primers: 5'-ATGCAGACGATCAAGTGCG-3', 5'-TTCAGTCCCTTCTGCGTCA-3'; reaction: $30 \mathrm{~s}$ at $94^{\circ} \mathrm{C}, 45 \mathrm{~s}$ at $53^{\circ} \mathrm{C}, 35 \mathrm{~s}$ at $72^{\circ} \mathrm{C} ; 28$ cycles), the relative expression levels of $\mathrm{kgb}-1$ (5'-GGAACTGTCGTAATGGCCGATG-3', 5'-CGGCAAAATCAATTTCCTGATC-3'; $30 \mathrm{~s}$ at $94^{\circ} \mathrm{C}, 45 \mathrm{~s}$ at $61^{\circ} \mathrm{C}, 60 \mathrm{~s}$ at $72^{\circ} \mathrm{C} ; 29 \mathrm{cycles}$ ), jun-1a-e (5'-ATGGCACTCGATGACCAAGA-3', $5^{\prime}$-CACGAATCGAATTGTTCGGGC-3'; $30 \mathrm{~s}$ at $94^{\circ} \mathrm{C}, 45 \mathrm{~s}$ at $52^{\circ} \mathrm{C}, 15 \mathrm{~s}$ at $72^{\circ} \mathrm{C} ; 30$ cycles), and fos- 1 were determined. In case of $f o s-1$, there are two overlapping splice variants $(f o s-1 a$, fos- $1 b)$, which cannot be clearly separated by PCR. Therefore, PCR was carried out for both fos-1a and fos-1b simultaneously (fos-1ab) (5'-TGGCGGAATGCAACAACATCCGA-3', 5'-GTCGAATGGGCCTGGTGGGC-3'; $30 \mathrm{~s}$ at $94^{\circ} \mathrm{C}, 45 \mathrm{~s}$ at $55^{\circ} \mathrm{C}, 42 \mathrm{~s}$ at $72^{\circ} \mathrm{C} ; 29$ cycles). Quantification and analysis of band intensities were made using ImageJ.

\section{GPDH activity assay}

Synchronized (young) adult worms were incubated for different times (0-24 h) on test (standard $\mathrm{NaCl}$ concentration plus $200 \mathrm{mmol} / \mathrm{L} \mathrm{NaCl}$ ) plates (NGM plates, seeded with E. coli OP50). After incubation, worms were washed off and cleaned several times with washing medium to exclude bacteria. The samples were centrifuged $\left(4^{\circ} \mathrm{C}, 1500 \mathrm{xg}\right)$, and the supernatant removed. The worm pellet was weighed and estimating $1 \mathrm{mg}$ as $1 \mu \mathrm{l}, 1.5$ volumes of lysis-buffer (100 mmol/L Glycine-NaOH pH 9.0, $5 \mathrm{mmol} / \mathrm{L}$ EDTA, $0.9 \mathrm{~mol} / \mathrm{L}$ glycerin, $2 \mathrm{mmol} / \mathrm{L}$ PMSF) were added, with the samples then frozen in liquid nitrogen. After thawing on ice, samples were homogenized using a Teflon ${ }^{\circledR}$ pistil, centrifuged $\left(4^{\circ} \mathrm{C}, 16000 \mathrm{xg}\right)$ to remove insoluble material, and protein concentration of the supernatant determined using the Bradford assay. GPDH activity was determined via the reverse reaction: dihydroxyacetone phosphate $+\mathrm{NAD}^{+} \rightarrow$ glycerol-3-phosphate (G3P) + NADH. For each measurement, $250 \mu \mathrm{l}$ Borax solution ( $25 \mathrm{mmol} / \mathrm{L})$ and $67 \mu \mathrm{l} \mathrm{H} \mathrm{O}_{2}$ were pre-warmed to $30^{\circ} \mathrm{C}$. Then, a $100 \mu \mathrm{l}$ sample was added, followed by the addition of $50 \mu \mathrm{l} \mathrm{NAD}{ }^{+}(50 \mathrm{mmol} / \mathrm{L}$; after $3 \mathrm{~min})$ and 33 $\mu \mathrm{l} \mathrm{G3P}$ solution (150 mmol/L; after $6 \mathrm{~min}$ ). The increase in NADH absorbance was measured at $\lambda=340 \mathrm{~nm}$. The specific GPDH activity (nkat/mg protein) resulted from the slope of the NADH absorbance curve, with the extrapolated $\mathrm{NAD}^{+}$baseline substracted and the data normalized with respect to protein concentration. 


\section{Cellular Physiology and Biochemistry}

Cell Physiol Biochem 2014;34:1951-1973

\begin{tabular}{l|l}
\hline DOI: $10.1159 / 000366392$ & (C) 2014 S. Karger AG, Basel
\end{tabular}

\begin{tabular}{l|l} 
Published online: November 25, 2014 & www.karger.com/cpb
\end{tabular}

Gerke et al.: The JNK-Like MAPK KGB-1 of C. Elegans

Data bases

DEGs were classified according to WormBase (http://www.wormbase.org/\#01-23-6) and KOG (Eukaryotic clusters of orthologous groups) (http://www.ncbi.nlm.nih.gov/COG/). Transport DB (www. membranetransport.org; [38]) was used to detect genes for membrane transporters in the transcriptome data.

Statistical analysis

Data are given as means \pm standard deviation (S.D.) or means of means \pm standard error of the mean (S.E.M.) with $n$ indicating the number of analyzed plates or the number of experiments. Lifespan was determined with the Kaplan-Meier estimator, and statistical significances were checked using the logrank test. t-tests were applied to test for differences between control and/or test conditions, and oneway analysis of variance (ANOVA) with a subsequent multiple comparison procedure (Student NewmanKeuls method) was used to test for differences in time courses or $\mathrm{NaCl}$ concentration series. The chosen significance level was $P<0.05$. Enrichment analyses (i.e., chi-square tests; Microsoft Excel 2007) were done to identify KOG categories with the ratio between up-regulated and total DEGs with KOG identity (KOG ID) deviating highly significantly $(P<0.001)$ or significantly $(P<0.05)$ from the corresponding overall ratio of the two evaluated contrasts $\left(\mathrm{WT}_{\mathrm{ho}} / \mathrm{WT}_{\mathrm{ctrl}}: 448\right.$ vs $\left.700 \mathrm{DEGs} ; \mathrm{kg} b-1 \Delta_{\mathrm{ho}} / \mathrm{WT}_{\mathrm{ho}}: 801 \mathrm{vs} 1171 \mathrm{DEGs}\right)$. The gene functional classification tool (DAVID Bioinformatics Resources 6.7, http://david.abcc.ncifcrf.gov/home.jsp) was used to cluster all up- or down-regulated DEGs of the two contrasts (with simultaneous computation of group enrichment scores, GES). SigmaPlot 11.0 (Systat Software, Erkrath, Germany) was used for graph preparations and other statistical analyses.

\section{Results}

KGB-1 expression

KGB-1 expression was studied using transcriptional $\left(P_{k g b-1}:: g f p ;\right.$ Fig. $\left.1 \mathrm{~A}, \mathrm{~B}\right)$ and translational $\left(P_{k g b-1}-k g b-1:: g f p ;\right.$ Fig. $\left.1 C\right)$ reporters. Eggs already showed the corresponding GFP fluorescence (Fig. 1A), with more and more tissues following during development (L1 larval stage: pharynx, excretory cell, some sensory neurons; L2-L4 larval stages: intestine, rectal sensory neurons; adult worms: longitudinal muscles, gonads). The rare males showed GFP expression in their spermathecae. Within the anterior part of the nervous system, GFP expression was detected in the pharyngeal nerve ring and in some sensory neurons (Fig. 1B, a1-a3). Within its posterior part, lumbar ganglia and the dorso-rectal ganglion showed GFP expression (Fig. 1B, p).

Reproduction rate and lifespan at moderate hyperosmolarity

Moderate (i.e., non-lethal) hyperosmolarity (200 mmol/L $\mathrm{NaCl}$ ) impaired reproduction

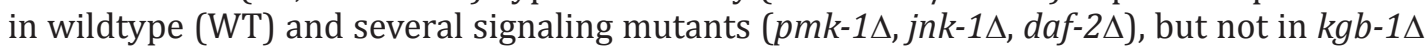
(Fig. 2B). Under control conditions, however, the level of offspring was lower in $\mathrm{kg} b-1 \Delta$ (and $p m k-1 \Delta, d a f-2 \Delta$ ) than in WT. $k g b-1 \Delta$ and $d a f-2 \Delta$ also showed a time delay in egg-laying by one day at moderate hyperosmolarity (Fig. 2A). Moderate hyperosmolarity impaired lifespan in WT, $j n k-1 \Delta$, and $d a f-2 \Delta$, but not in $k g b-1 \Delta$ (Fig. 2C). However, the lifespan of $k g b-1 \Delta$ was already short under control conditions. Hence, reproduction rate is low and lifespan short in $k g b-1 \Delta$ but in both cases unaffected by moderate hyperosmolarity.

\section{Survival rate at severe hyperosmolarity}

Testing the tolerance to severe hyperosmolarity showed $k g b-1 \Delta$ and $d a f-2 \Delta$ to survive $400 \mathrm{mmol} / \mathrm{L} \mathrm{NaCl}$ and higher salt concentrations (24 hours) much better than WT, whereas the survival rates of $p m k-1 \Delta$ and $j n k-1 \Delta$ did not differ from WT (Fig. 3A). Another test series with $400 \mathrm{mmol} / \mathrm{L} \mathrm{NaCl}$ (24 hours) confirmed the improved survival rate of $\mathrm{kg} b$ - $1 \Delta$ and $d a f$ -

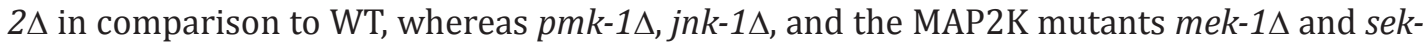
$1 \Delta$ did not survive hyperosmolarity better than WT (Fig. 3B). Similar results were obtained by RNAi experiments, which showed $\mathrm{kg} b$-1-RNAi to enhance the survival rate at $400 \mathrm{mmol} / \mathrm{L}$ 


\section{Cellular Physiology and Biochemistry}

Cell Physiol Biochem 2014:34:1951-1973

\begin{tabular}{l|l}
\hline DOI: $10.1159 / 000366392$ & (C) 2014 S. Karger AG, Basel
\end{tabular}

Published online: November 25, $2014 \quad$ www.karger.com/cpb

Gerke et al.: The JNK-Like MAPK KGB-1 of C. Elegans

Fig. 1. KGB-1 expression. (A) The transcriptional reporter $P_{k g b-1}:: g f p$ was expressed in eggs, L1 larvae (P: pharynx, E: excretory cell, SN: sensory neurons), from L2 stage onwards in intestinal cells (I) and rectal sensory neurons ( $\mathrm{rSN}$ ), and in longitudinal muscles (M) and mature gonads of adult worms (horizontal bars, $20 \mu \mathrm{m}$ ). (B) $P_{k g b \text { - }}$ $:: g f p$ was expressed in anterior (a1-a3) and posterior (p) parts of the nervous system (SN, SD: nuclei and dendrites of sensory neurons, NR: pharyngeal nerve ring, DRG: dorso-rectal ganglion, $\mathrm{LG}(\mathrm{r}, \mathrm{l})$ : right and left lumbar ganglia). (C) The translational reporter $P_{k g b-1}-$ $k g b-1:: g f p$ showed an expression pattern similar to that of the transcriptional reporter (P: pharynx, G: gonads).

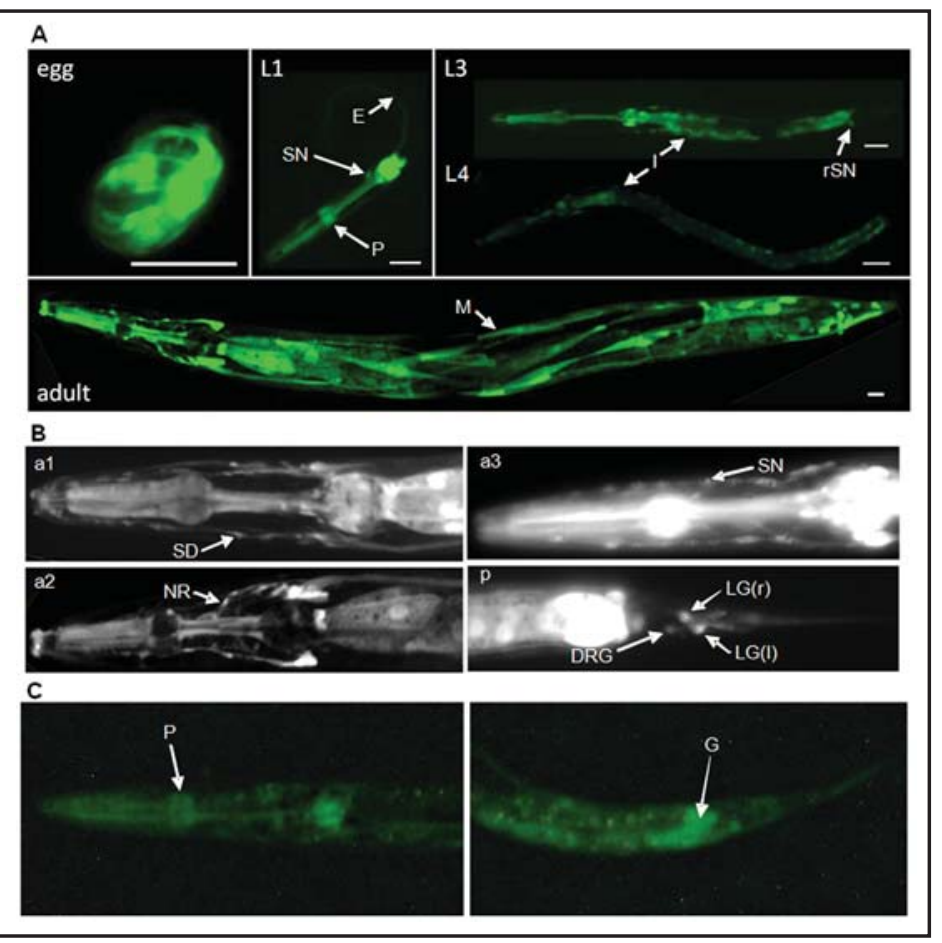

Fig. 2. Reproduction and lifespan at moderate hyperosmolarity. (A) Daily or (B) total numbers of offspring per worm and $(C)$ lifespan of WT, $k g b-1 \Delta, p m k-1 \Delta$, jnk-1 $d a f-2 \Delta$ at control (white areas/ bars) or hyperosmotic conditions (200 mmol/L NaCl; dotted areas/ bars). (A, B: means \pm S.D.; C: Kaplan-Meier curves; per condition and strain, $n=8-13$ plates with one worm each.) Asterisks indicate significant differences between control and hyperosmotic conditions; small letters $(a, b)$ mark significant differences between WT and mutants either at control or hyperosmotic conditions $(P<$ 0.05).

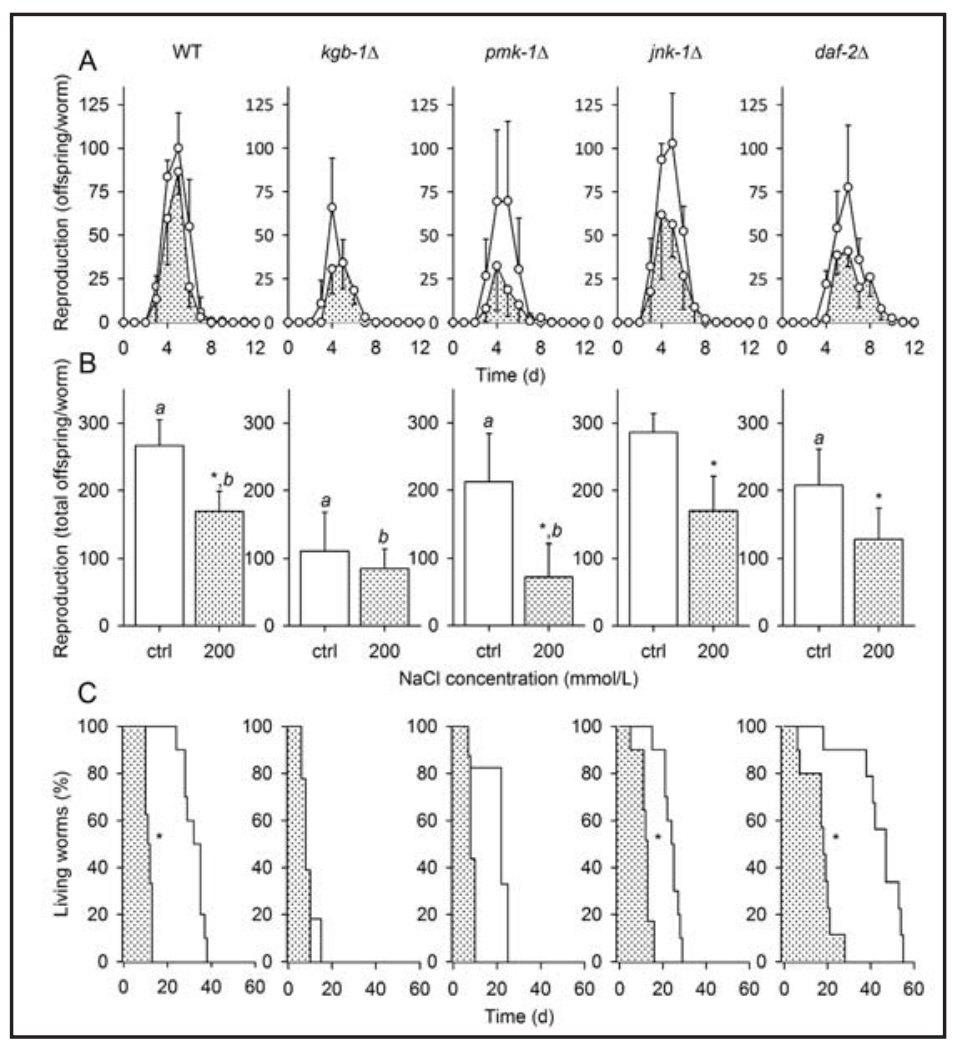

$\mathrm{NaCl}$ (24 hours), whereas sek-1-RNAi in WT or mek-1s did not improve hyperosmotic tolerance in comparison to the control- (ctrl-) RNAi treated equivalents (Fig. 3C). Thus, the knock-out (mutant) or knock-down (RNAi) of KGB-1 and DAF-2 expression promote the tolerance to severe hyperosmolarity. 


\section{Cellular Physiology and Biochemistry}

Cell Physiol Biochem 2014;34:1951-1973

Fig. 3. Survival at severe hyperosmolarity. (A) Survival rates of WT (dotted areas),

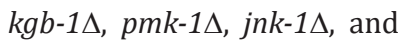
daf- $2 \Delta$ after 24 hours at different osmotic conditions (0-700 mmol/L NaCl). (B) Survival rates of $\mathrm{WT}, k g b$ $1 \Delta, p m k-1 \Delta, j n k-1 \Delta$, mek-1

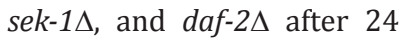
hours at control (white bars) or hyperosmotic conditions (400 mmol/L NaCl; dotted bars). (C) Survival rates of RNAi-treated WT (ctrl-RNAi, kgb-1-RNAi, sek-1-RNAi), $k g b-1 \Delta$ (ctrl-RNAi), and mek$1 \Delta$ (ctrl-RNAi, sek-1-RNAi) after 24 hours at control (white bars) or hyperosmotic conditions (400 mmol/L NaCl; dotted bars). (Means \pm S.D.; per condition and strain/treatment, $n=5-37$ plates with 10 worms each.) Asterisks indicate significant differences
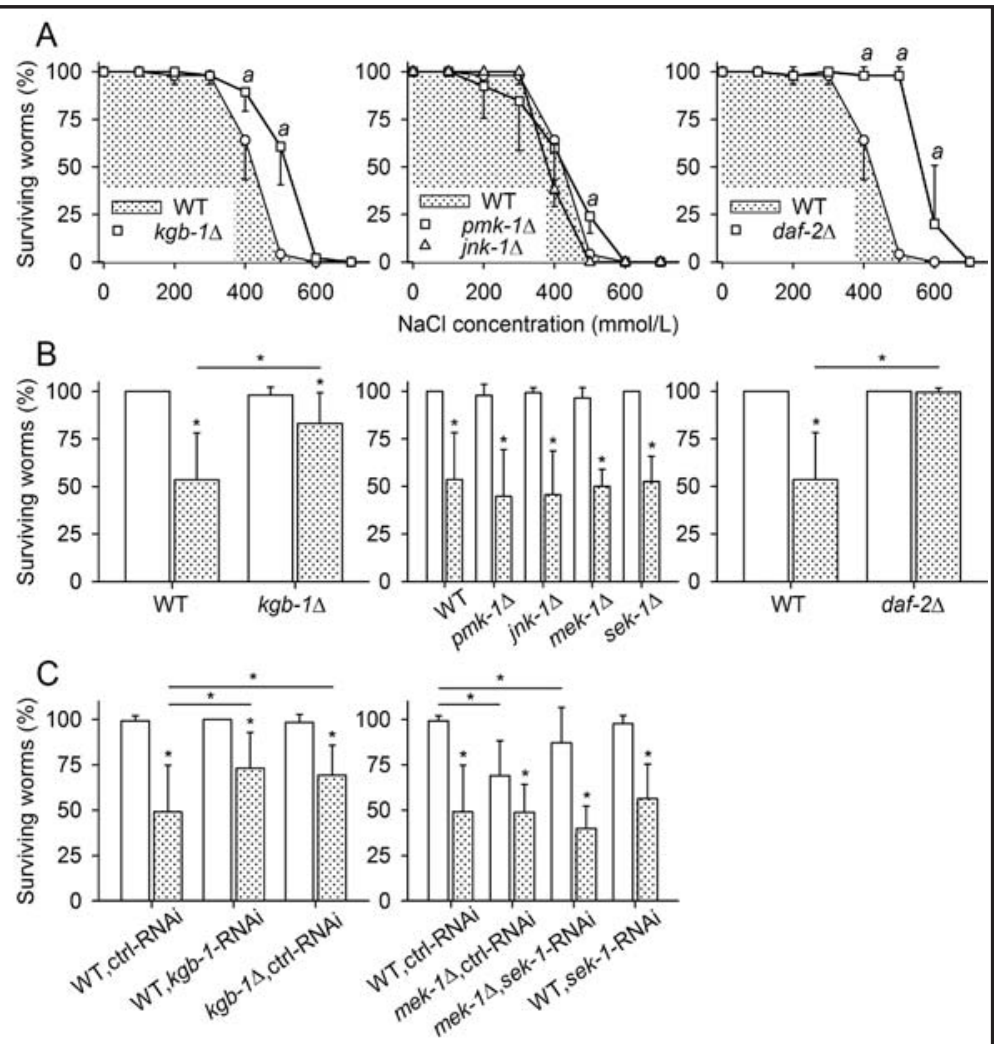

between control and hyperosmotic conditions; small letters $(a)$ or asterisks and bars mark significant differences between WT and mutants or different RNAi-treatments $(P<0.05)$.

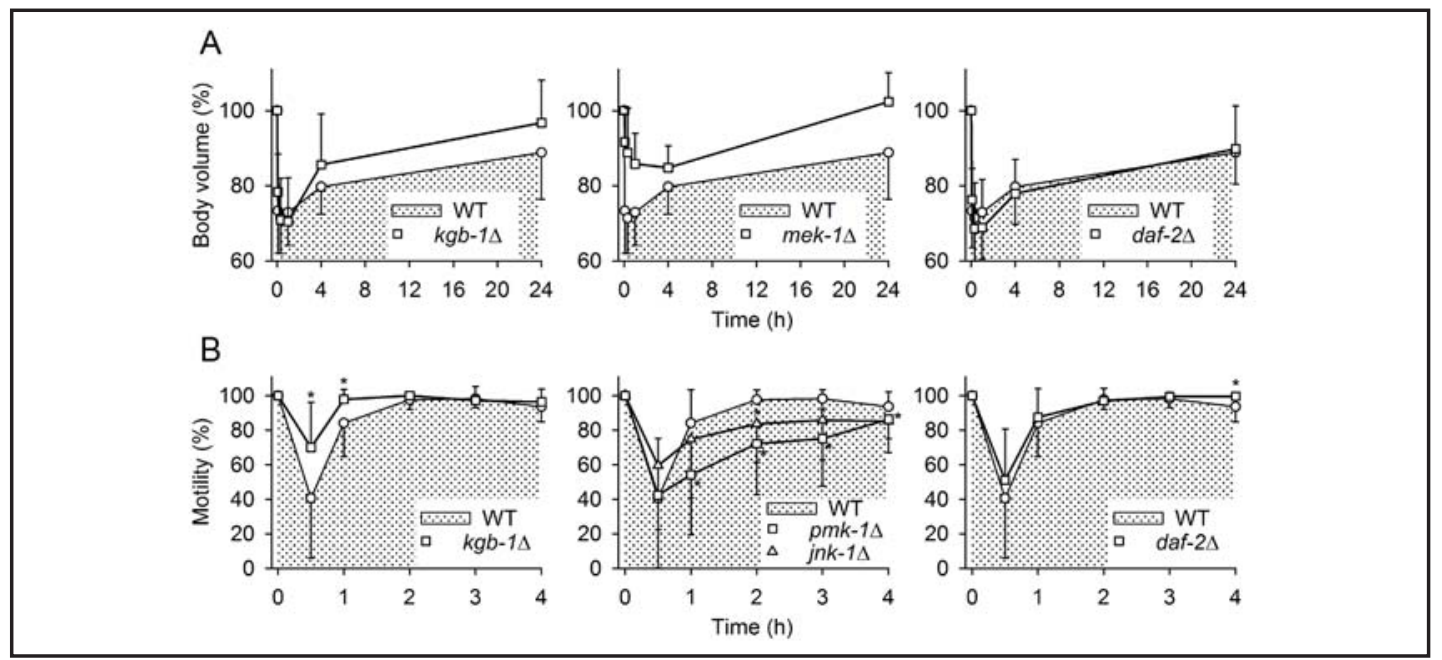

Fig. 4. Body volume and motility at acute and severe hyperosmolarity. Changes in (A) body volume and (B) motility (normalized data; initial values $=100 \%$ ) after transferring WT (dotted areas), $k g b-1 \Delta$, and daf-2 as well as (A) $m e k-1 \Delta$ or (B) $p m k-1 \Delta$ and $j n k-1 \Delta$ from control (time: $0 \mathrm{~h}$ ) to hyperosmotic conditions (400 $\mathrm{mmol} / \mathrm{L} \mathrm{NaCl}$ ). (Means \pm S.D.; per strain, either (A) $n=5-16$ experiments on one worm each or (B) $n=14-20$ plates with 10 worms each.) Asterisks indicate significant differences between WT and mutants $(P<0.05)$.

Body volume and motility at acute and severe hyperosmolarity

Studying effects of acute and severe hyperosmolarity (400 mmol/L $\mathrm{NaCl}$ ) on body volume and motility showed for both variables initial decreases (0-1 hour) and subsequent 


\section{Cellular Physiology $\quad$ Cell Physiol Biochem 2014;34:1951-1973

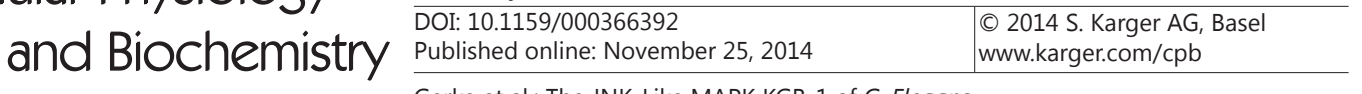

Fig. 5. Glycerol-3-phosphate dehydrogenase (GPDH) activity at moderate hyperosmolarity. (A) Changes in GPDH activity after transferring WT (dotted area) and $k g b-1 \Delta$ from control (time: $0 \mathrm{~h}$ ) to hyperosmotic conditions (200 mmol/L NaCl). (B) GPDH activity after 24 hours at control (white bars) or hyperosmotic conditions (200 mmol/L NaCl; dotted bars) in WT, $k g b-1 \Delta$, $p m k-1 \Delta$, and $j n k-1 \Delta$. (Means \pm S.E.M.; per condition and strain, $n=3$ plates with several hundred worms each.) Asterisks indicate significant differences between control and hyperosmotic conditions; small letters $(a)$ or asterisks and bars mark significant differences between WT and mutants $(P<0.05)$.

Fig. 6. Effects of KGB-1 and hyperosmolarity on $\mathrm{kgb}$ 1, jun-1, and fos-1 expression. Levels of (A) $\mathrm{kgb}-1$ mRNA, (B, C) jun-1a-e mRNA, (D, E) fos-1ab mRNA and (F) ECFP fluorescence intensity from the expressed transcriptional reporter $P_{f o s-1}:$ ecfp in (A, B, D, F) WT and (C, E) $k g b-1 \Delta$ after three hours (mRNA) or three and 24 hours (protein) at hyperosmotic conditions $(200,300$, and $400 \mathrm{mmol} / \mathrm{L} \mathrm{NaCl}$; all data sets normalized with respect to control conditions (=100\%)). (G) $P_{\text {fos }-1}$-dependent ECFP expression in the posterior worm region after 24 hours at control or hyperosmotic conditions (200 mmol/L NaCl). (Means \pm (A-E) S.E.M. or (F) S.D.; per condition and strain, either (A-E) $n=3$ plates with several hundred worms each or (F) $n=5-10$ plates with one worm each.) Asterisks and bars indicate significant differences in expression level; small letters $(a)$ mark significant differences between WT and $\mathrm{kgb}-1 \Delta$ $(P<0.05)$.
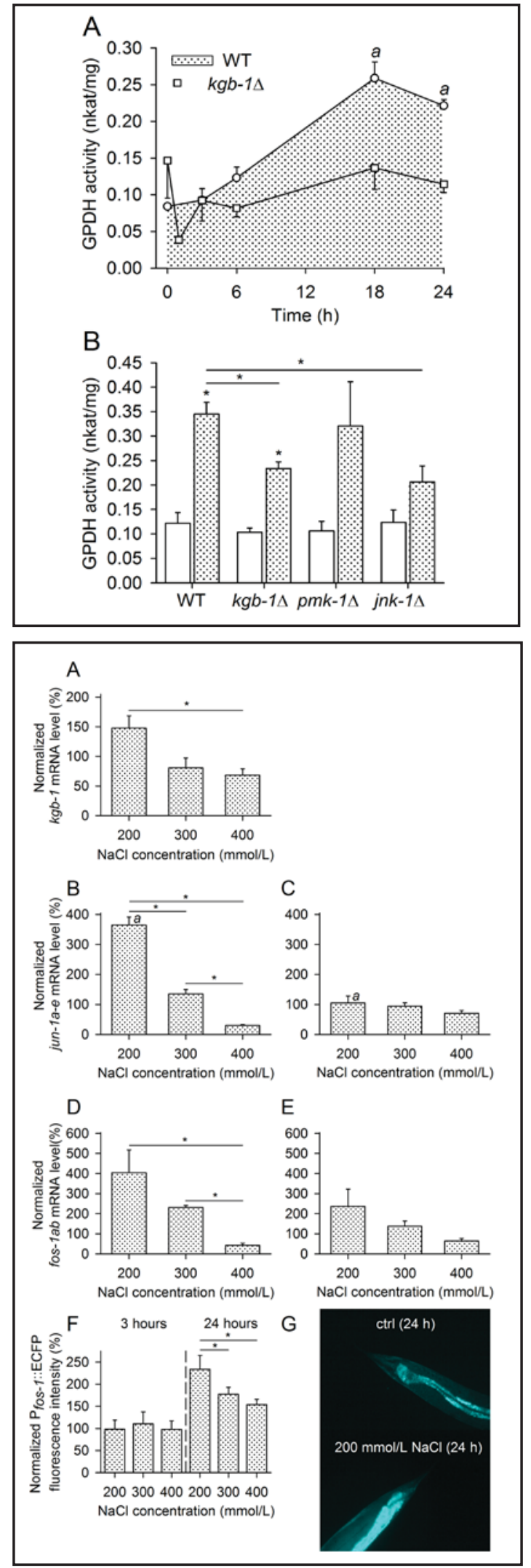

increases (0.5-24 hours) (Fig. 4). The return to initial values was faster in $\mathrm{kg} b-1 \Delta$ than in WT (Fig. 4A, B). The MAP2K mutant mek-1 $\Delta$ showed only a small initial decrease in 


\section{Cellular Physiology and Biochemistry}

Cell Physiol Biochem 2014;34:1951-1973

DOI: 10.1159/000366392

(C) 2014 S. Karger AG, Basel

www.karger.com/cpb

Gerke et al.: The JNK-Like MAPK KGB-1 of C. Elegans
Fig. 7. FOS-1 and hyperosmotic tolerance. Survival rates of (A) RNAi-treated WT (ctrl-RNAi, $k g b$-1-RNAi, fos-1-RNAi) and $k g b-1 \Delta$ (ctrl-RNAi, fos-1-RNAi) or (B) WT and fos-1 $\Delta$ after 24 hours at control (white bars) or hyperosmotic conditions $(400 \mathrm{mmol} / \mathrm{L} \mathrm{NaCl}$; dotted bars). (C) Percentage of RNAi-treated (ctrl-RNAi, kgb-1-RNAi, fos-1-RNAi) DAF-16::GFP expressing worms (strain TJ356) with exclusively cytoplasmic DAF-16::GFP after 24 hours at control (white bars) or hyperosmotic conditions $(400 \mathrm{mmol} / \mathrm{L} \mathrm{NaCl}$; dotted bars). (Means \pm S.D.; per condition and strain/ treatment, $n=5-37$ plates with 5-10 worms each.) Asterisks indicate significant differences between control and hyperosmotic conditions (C only); asterisks and bars mark significant differences between WT, mutant or different RNAi-treatments $(P<0.05)$.

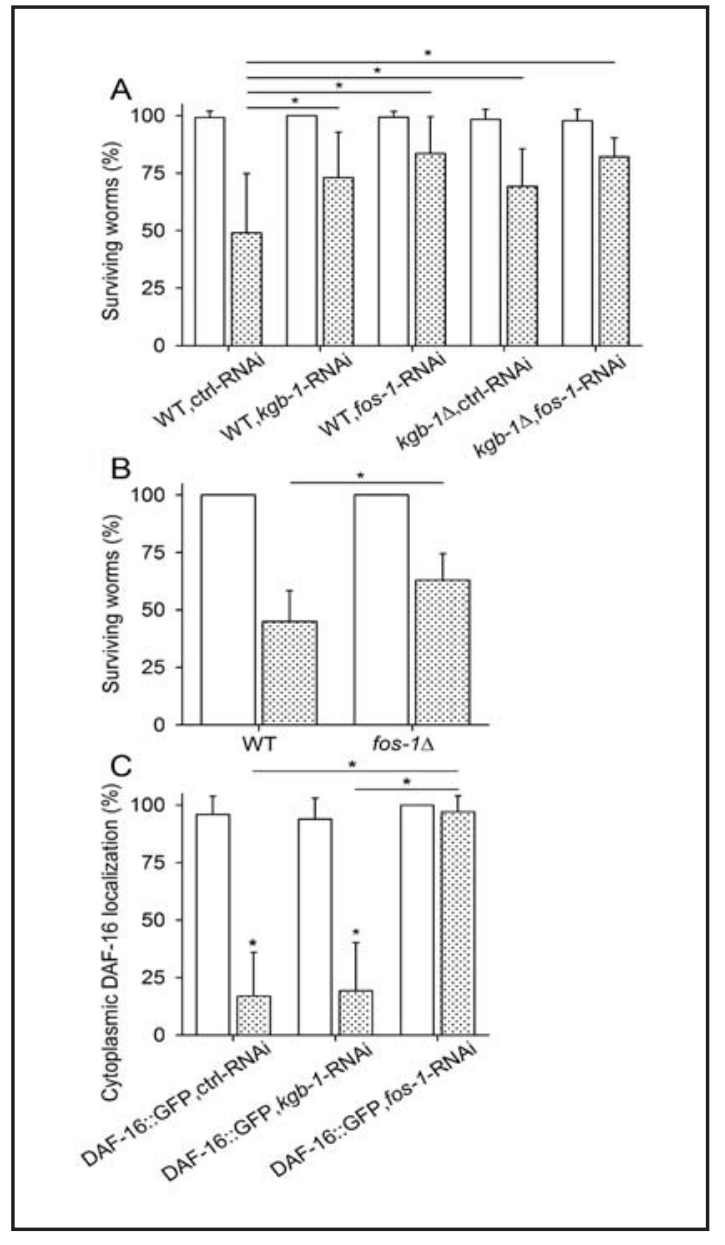

body volume, and the recovery of body volume and/or motility was similar or inferior in $p m k-1 \Delta$, jnk-1 $\Delta$, and $d a f-2 \Delta$ in comparison to WT. Consequently, $k g b-1 \Delta$ recovers faster than WT from the acute effects of severe hyperosmolarity on body volume and motility.

\section{GPDH activity at moderate hyperosmolarity}

Differences in hyperosmotic tolerance can be caused by differences in the activity of glycerol-3-phosphate dehydrogenase (GPDH), which is rate limiting for synthesis of the important compatible osmolyte glycerol. GPDH activity was determined upon acute and moderate hyperosmolarity (200 mmol/L NaCl). Similar to previously measured time courses of glycerol accumulation [39], GPDH activity increased in WT after approximately three hours reaching maximal levels after 18-24 hours (Fig. 5A). In $k g b-1 \Delta$, GPDH activity changed only slightly during this period. Another test series with $200 \mathrm{mmol} / \mathrm{L} \mathrm{NaCl}$ (24 hours) showed a stronger increase in GPDH activity in WT (and $p m k-1 \Delta$ ) in comparison to $k g b-1 \Delta$ (and jnk$1 \Delta$ ) (Fig. 5B). Thus, the higher hyperosmotic tolerance of $k g b-1 \Delta$ is not based on elevated GPDH activity and glycerol synthesis.

\section{jun-1 and fos-1 expression: effects of hyperosmolarity and $\mathrm{kgb}-1$ mutation}

JNK promotes the expression of jun-1 and fos-1 [40], which code for AP-1 transcription factor elements [41]. Consequently, we checked whether jun-1 and fos-1 expression are likewise affected by the JNK-like MAPK KGB-1. In addition, we tested effects of different levels of hyperosmolarity $(200,300,400 \mathrm{mmol} / \mathrm{L} \mathrm{NaCl})$. Rising hyperosmolarity caused the mRNA levels of $k g b-1, j u n-1 a-e$, and fos-1ab in WT to decrease (Fig. 6A, B, D) and of jun-1a-e and fos$1 a b$ in $\mathrm{kgb}-1 \Delta$ to show a trend towards a decrease (Fig. 6C, E). Moderate hyperosmolarity, 
Fig. 8. DAF-16 and hyperosmotic tolerance. (A) DAF-16::GFP cellular localizations in the transgenic strain TJ356 after 24 hours at control (ctrl; left) or hyperosmotic conditions $(400 \mathrm{mmol} / \mathrm{L} \mathrm{NaCl}$; center) and in the control animals after one additional hour at $37^{\circ} \mathrm{C}$ (right). (B) Survival rates of WT (dotted area) and TJ356 (squares) as well as the percentage of worms with exclusively cytoplasmic DAF-16::GFP (triangles) after 24 hours at different

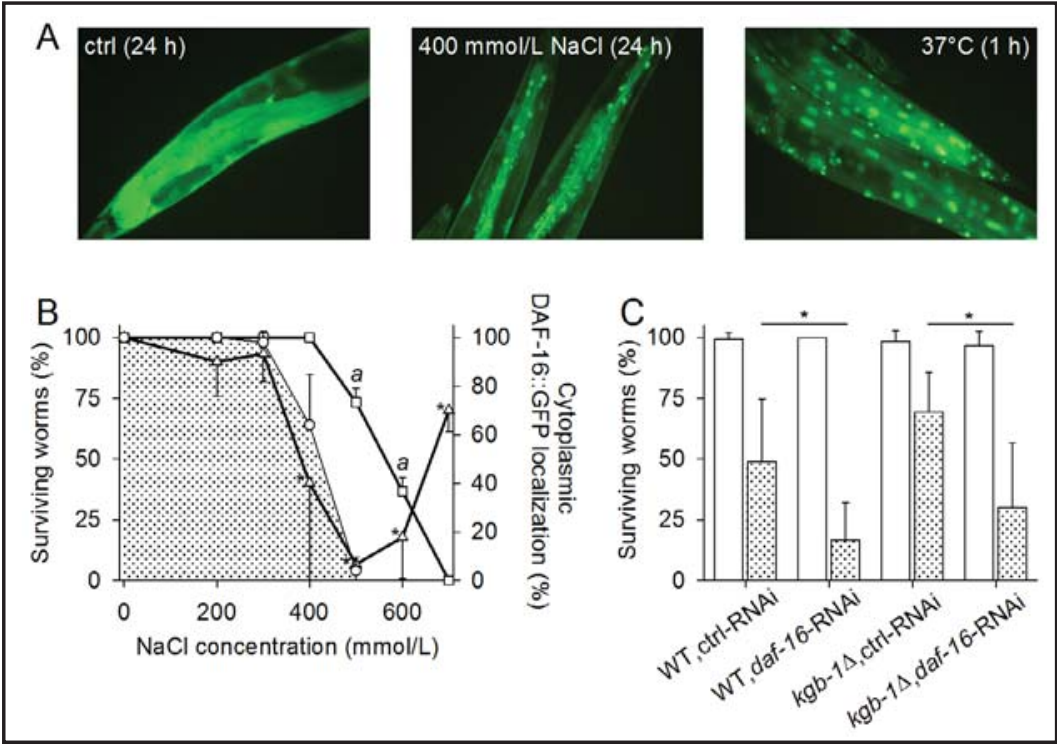
osmotic conditions (0-700 mmol/L NaCl). (C) Survival rates of RNAi-treated WT (ctrl-RNAi, daf-16-RNAi) and $k g b-1 \Delta$ (ctrl-RNAi, daf-16-RNAi) after 24 hours at control (white bars) or hyperosmotic conditions (400 $\mathrm{mmol} / \mathrm{L} \mathrm{NaCl}$; dotted bars). (Means \pm S.D.; per condition and strain/treatment, $n=3-37$ plates with 5-10 worms each.) Asterisks indicate significant differences to the control condition (0 mmol/L $\mathrm{NaCl})$ in DAF16::GFP localization; small letters $(a)$ or asterisks and bars mark significant differences in survival rate between WT and TJ356 or between different RNAi-treatments $(P<0.05)$.

however, often evoked higher expression levels in comparison to control values (normalized levels greater than 100\%). In $k g b-1 \Delta$, mRNA levels (moderate hyperosmolarity) were lower (jun-1a-e; Fig. 6B, C) or tended to be lower (fos-1ab; Fig. 6D, E) than in WT. The significant decrease in $P_{f o s-1}$-dependent protein (ECFP) expression with increasing hyperosmolarity (24-hour incubations; Fig. 6F, G) was in line with the decrease in fos-1ab mRNA expression (Fig. 6D). Thus, severe hyperosmolarity impairs the expression of $k g b-1$, jun-1, and fos-1, and KGB-1 (in WT) promotes the expression of jun-1 and likely fos-1.

\section{Hyperosmotic tolerance and FOS-1}

fos-1-RNAi enhanced the hyperosmotic tolerance ( $400 \mathrm{mmol} / \mathrm{L} \mathrm{NaCl}, 24$ hours) of $C$. elegans even a little more than $\mathrm{kgb}-1$-RNAi or $\mathrm{kgb}-1 \Delta$ (Fig. 7A), and fos-1 $\Delta$ showed a higher hyperosmotic tolerance than WT (Fig. 7B). Moreover, fos-1-RNAi prevented, in contrast to control- and $\mathrm{kgb}$-1-RNAi, nuclear DAF-16::GFP translocations in TJ356 (a DAF-16::GFP expressing transgenic strain) at severe hyperosmolarity ( $400 \mathrm{mmol} / \mathrm{L} \mathrm{NaCl}, 24$ hours) (Fig. 7C) indicating DAF-16 target (stress) gene expression not to be necessary in case of fos-1RNAi. Blocked FOS-1 expression promotes the hyperosmotic tolerance of $C$. elegans even more than missing KGB-1, which is in line with the reported downward control of FOS-1 by KGB-1 $[25,28]$.

\section{Hyperosmotic tolerance and the DAF-2 pathway}

To assess contributions of the DAF-2 pathway to hyperosmotic tolerance, nuclear DAF16::GFP translocations were studied in TJ356 together with survival rates of WT and TJ356 at different hyperosmotic conditions (24 hours; Fig. 8A, B). The DAF-16 overexpressing TJ356 ( $P_{\text {daf-16 }}-$ daf-16::gfp [24]) survived higher salt concentrations $(500-600 \mathrm{mmol} / \mathrm{L} \mathrm{NaCl})$ better than WT. Nuclear DAF-16::GFP translocations were detected at $400 \mathrm{mmol} / \mathrm{L} \mathrm{NaCl}$ and higher salt concentrations (Fig. 8A, B), with the level of nuclear DAF-16::GFP decreasing again at $700 \mathrm{mmol} / \mathrm{L} \mathrm{NaCl}$. daf-16-RNAi affected the hyperosmotic tolerance of WT as well as $k g b-1 \Delta$ negatively (Fig. 8C). Hence, the expression of DAF-16 target genes improves the tolerance to severe hyperosmolarity. 
Fig. 9. KOG-classified DEGs in case of $\mathrm{WT}_{\mathrm{ho}} / \mathrm{WT}_{\mathrm{ctrl}}$ and $k g b-1 \Delta_{\text {ho }} / \mathrm{WT}_{\mathrm{ho}}$. Numbers of up- or down-regulated differentially expressed genes (DEGs; false discovery rate, FDR < 0.005) within the different KOG (eukaryotic orthologous groups) categories for (A) $\mathrm{WT}_{\text {ho }} / \mathrm{WT}_{\text {ctrl }}$ and (B) $\mathrm{kgb}-1 \Delta_{\text {ho }} / \mathrm{WT}_{\text {ho. }}$ KOG categories with the ratio between up-regulated and total DEGs deviating highly significantly $(P<0.001)$ from the overall ratio between up-regulated and total DEGs are indicated by dark-gray bars (gray bars, $P$ $<0.05)$.

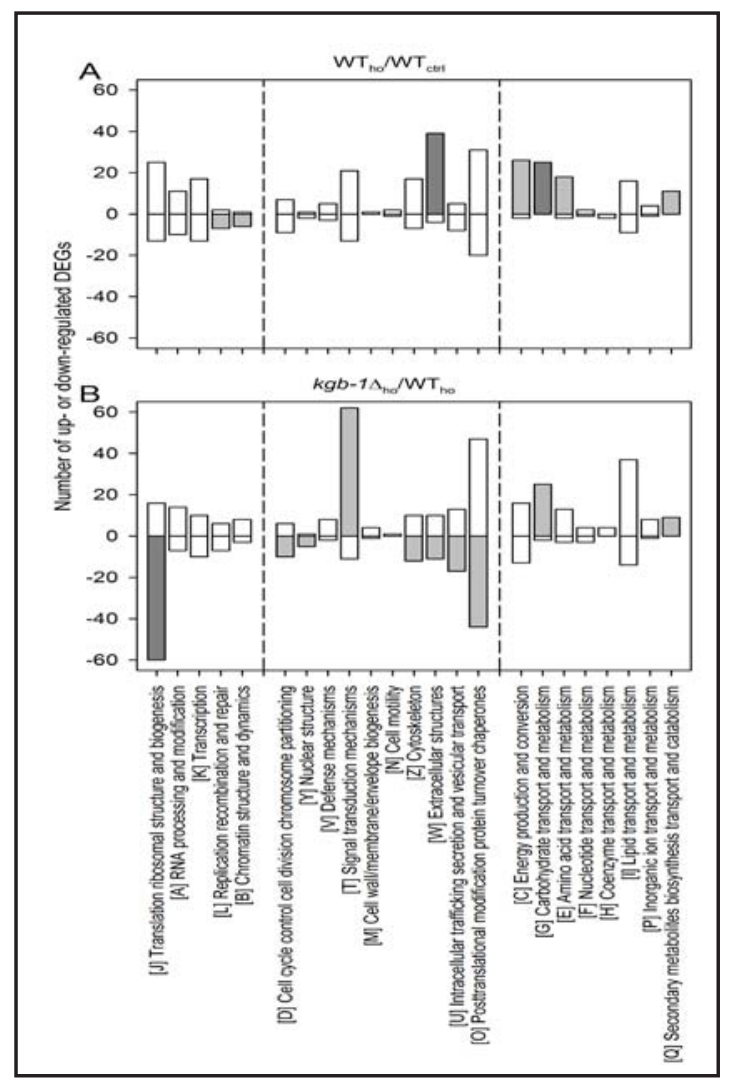

Transcriptomics by RNA-Seq

To further elucidate transcriptional responses to severe hyperosmolarity (see [42] for responses to moderate hyperosmolarity) as well as KGB-1-dependent effects on gene expression, transcriptome profiling by RNA-Seq was carried out to contrast 1) severe hyperosmotic (ho; $400 \mathrm{mmol} / \mathrm{L} \mathrm{NaCl}, 3$ hours) and control conditions (ctrl) in $\mathrm{WT}\left(\mathrm{WT}_{\mathrm{ho}} / \mathrm{WT}_{\mathrm{ctrl}}\right)$ and 2) $\mathrm{kgb}-1 \Delta$ and WT at severe hyperosmolarity $\left(\mathrm{kgb}-1 \Delta_{\mathrm{ho}} / \mathrm{WT}_{\mathrm{ho}}\right)$. In case of $\mathrm{WT}_{\mathrm{ho}} / \mathrm{WT}_{\text {ctrl }}, 700$ differentially expressed genes (DEGs with a false discovery rate, FDR < 0.005) were detected (448 up-regulated and 252 down-regulated DEGs). For $\mathrm{kgb}-1 \Delta_{\mathrm{ho}} / \mathrm{WT}_{\mathrm{ho}}, 1171$ DEGs were found (801 up-regulated and 370 down-regulated DEGs). Their functional classification according to KOG (eukaryotic orthologous groups) resulted for $\mathrm{WT}_{\mathrm{ho}} / \mathrm{WT}_{\text {ctrl }}$ in 457 DEGs with KOG identity (KOG ID) and for $k g b-1 \Delta_{\text {ho }} / \mathrm{WT}_{\mathrm{ho}}$ in 610 DEGs with KOG ID. Thus, DEGs with KOG ID represented sufficiently large samples to classify them into higher-level KOG categories (Fig. 9). KOG enrichment analyses (i.e., chi-square tests) were carried out to identify KOG categories with the ratio between up-regulated and total DEGs deviating highly significantly $(P<0.001)$ from the corresponding overall ratio (WT $\mathrm{Wh}_{\mathrm{ho}} / \mathrm{WT}_{\mathrm{ctrl}}: 448$ vs $700 \mathrm{DEGs} ; \mathrm{kg} b-1 \Delta_{\mathrm{ho}} / \mathrm{WT}_{\mathrm{ho}}: 801$ vs 1171 DEGs). In case of $\mathrm{WT}_{\mathrm{ho}} / \mathrm{WT}_{\text {ctrr }}$ two $\mathrm{KOG}$ categories complied with this requirement ([W] Extracellular structures, $P \stackrel{\text { ctrr }}{=} 3.5 \mathrm{E}-04 ;[\mathrm{G}]$ Carbohydrate transport and metabolism, $P=$ 2.0E-04) (Fig. 9A; dark-gray bars). For $k g b-1 \Delta_{\mathrm{ho}} / \mathrm{WT}_{\mathrm{ho}}$, one category met this criterion ([J] Translation, ribosomal structure and biogenesis, $P=3.9 \mathrm{E}-17$ ) (Fig. 9B; dark-gray bar).

\section{Genetic inductions in WT and $\mathrm{kgb}-1 \Delta$ by severe hyperosmolarity}

In case of $\mathrm{WT}_{\text {ho }} / \mathrm{WT}_{\text {ctrl }}$ (Fig. 9A), the up-regulated genes of category [W] were mostly DEGs for type IV and XIII collagens (Fig. 10A) and in case of category [G], DEGs for UDPglucuronosyl and UDP-glucosyl transferases (including one UDP-glucose pyrophosphorylase) as well as DEGs for enzymes involved in trehalose metabolism (tps-2, tre-5) and membrane transports (R10D12.1, vglu-2) (Fig. 10B). With respect to all up-regulated DEGs from $\mathrm{WT}_{\text {ho }} /$ $\mathrm{WT}_{\text {ctrr }}$ the group enrichment score (GES; gene functional classification, DAVID 6.7) likewise 


\section{Cellular Physiology and Biochemistry}

Cell Physiol Biochem 2014;34:1951-1973

\begin{tabular}{l|l}
\hline DOI: $10.1159 / 000366392$ & C 2014 S. Karger AG, Basel
\end{tabular}

www.karger.com/cpb

Fig. 10. DEGs of two KOG categories strongly deviating from standard regulation in case of $\mathrm{WT}_{\text {ho }} / \mathrm{WT}_{\text {ctrl }}$ (see Fig. 9A). $\log _{2}-$ fold changes in the expression of up-regulated DEGs within the KOG categories (A) [W] Extracellular structures (gray bars: type IV and XIII collagens) and (B) [G] Carbohydrate transport and metabolism (gray bars: UDPglucuronosyl/-glucosyl transferases; dotted bars: genes for enzymes possibly involved in osmolyte synthesis and transport).
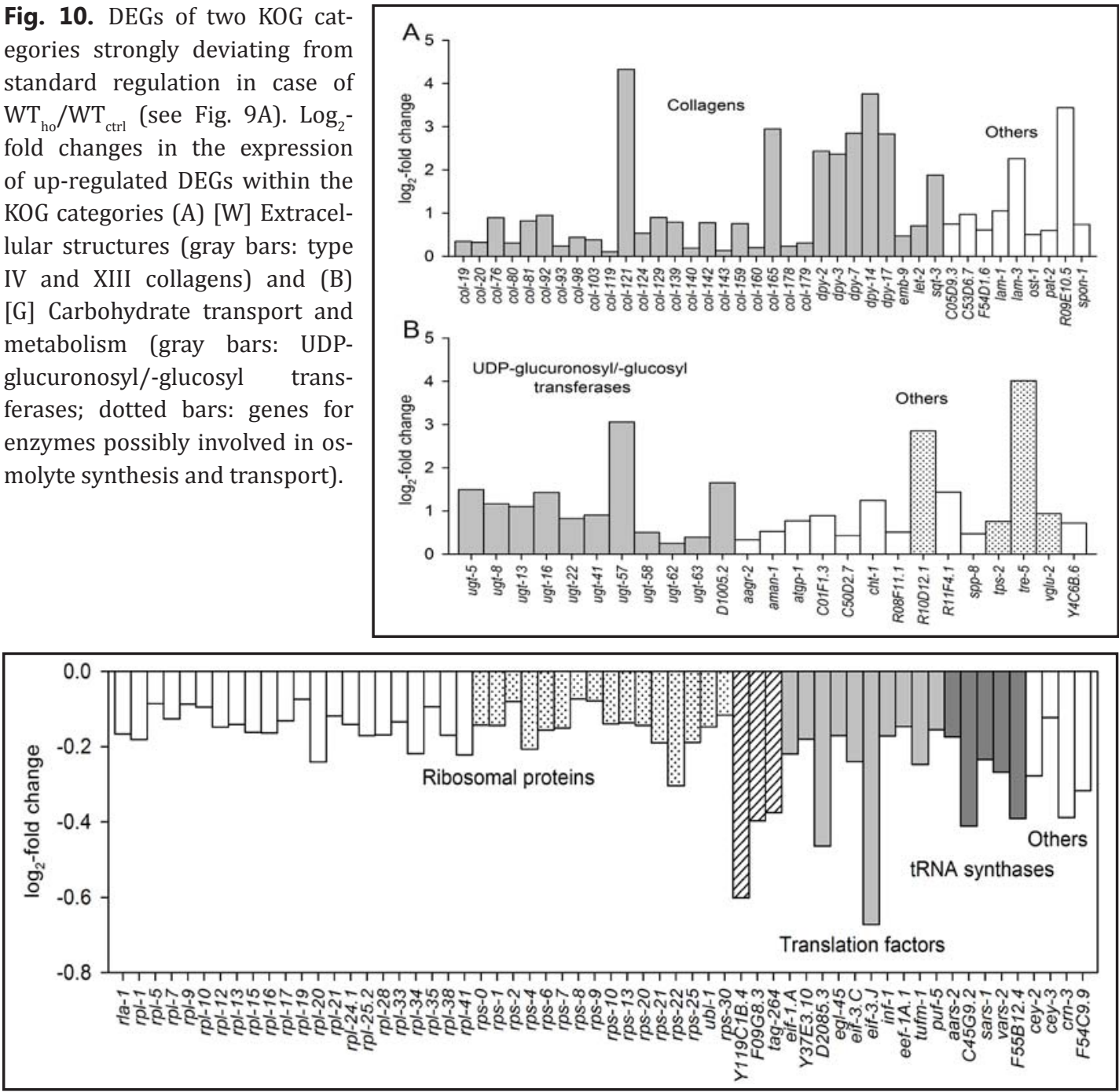

Fig. 11. DEGs of one KOG category strongly deviating from standard regulation in case of $k g b-1 \Delta_{\text {ho }} / \mathrm{WT}_{\text {ho }}$ (see Fig. 9B). $\log _{2}$-fold changes in the expression of down-regulated DEGs within the KOG category [J] Translation, ribosomal structure and biogenesis (white bars, different shadings: 60S, 40S, and mitochondrial ribosomal proteins; gray bars: translation factors; dark-gray bars: tRNA synthases).

turned out to be highest (GES $=6.6$ ) for a cluster consisting only of genes for type IV and XIII collagens (24 genes in total).

In case of $k g b-1 \Delta_{\text {ho }} / \mathrm{WT}_{\text {ho }}$ (Fig. 9B), the down-regulated genes of category [J] comprised twenty DEGs for 60S ribosomal proteins, sixteen DEGs for 40S ribosomal proteins, and three DEGs for mitochondrial ribosomal proteins (commonly referred to as ribosomal protein genes, $R P$ genes [43]) as well as ten DEGs for translation factors and five DEGs for tRNA synthases (commonly summarized as ribosome biogenesis genes, Ribi genes [43]) (Fig. 11). With respect to all down-regulated DEGs from $\mathrm{kgb}-1 \Delta_{\mathrm{ho}} / \mathrm{WT}_{\mathrm{ho}}$, the GES was indeed highest (22.1) for a cluster consisting of genes for eighteen $60 \mathrm{~S}$ ribosomal proteins, fourteen $40 \mathrm{~S}$ ribosomal proteins, three mitochondrial ribosomal proteins, and only two other proteins. The categories [T] and [0] also contained many DEGs (Fig. 9B), including eleven DEGs for serine/threonine/(tyrosine) kinases, four DEGs for tyrosine kinases, two DEGs for protein phosphatase 1 regulatory subunits, eighteen DEGs for tyrosine- or serine/threonine-specific protein phosphatases, and seven DEGs for C-type lectins (category [T]) as well as three DEGs for antioxidant/redox enzymes, seventeen DEGs for chaperones, and eleven DEGs for enzymes involved in ubiquitination/proteasomal degradation (category [0]). 
Table 1. DEGs in case of $\mathrm{WT}_{\mathrm{ho}} / \mathrm{WT}_{\text {ctrl }}$ (sequence, public gene name, function, $\log _{2}$-fold change, regulatory direction) for membrane transports and osmolyte syntheses identified using WormBase ${ }^{\mathrm{a}}$ and/or $\mathrm{KOG}^{\mathrm{b}}$, with asterisks indicating the respective false discovery rate $(*:<0.005 ; * *:<0.001)$

\begin{tabular}{|c|c|c|c|c|}
\hline Sequence & $\begin{array}{l}\text { Public } \\
\text { name }\end{array}$ & Function & $\log _{2}\left(\mathrm{WT}_{\mathrm{ho}} / \mathrm{WT}_{\text {ctrl }}\right)$ & Regulation \\
\hline \multicolumn{5}{|c|}{ Membrane transport } \\
\hline R10D12.1 & & $\begin{array}{l}\text { Permease of the major facilitator superfamily } \\
\text { [KOG2532] } ; 86.8 \% \text { homology to human vesicular } \\
\text { glutamate transporter } 2^{\text {a }}\end{array}$ & 2.8459 & Up** \\
\hline ZK550.2 & & $\begin{array}{l}\text { Predicted transporter/transmembrane protein } \\
\text { [KOG2325] }{ }^{;} ; 91.6 \% \text { homology to human major facilitator } \\
\text { superfamily domain-containing protein } 8^{a}\end{array}$ & 1.1917 & Up** \\
\hline K10G9.1 & vglu-2 & Vesicular glutamate transporter & 0.9313 & Up** \\
\hline Y32F6B.1 & & Organic anion transporter [KOG3626] ${ }^{\mathrm{b}}$ & 0.8459 & Up** \\
\hline F26D10.9 & atgp -1 & Predicted amino acid transporter glycoprotein subunit ${ }^{a}$ & 0.7662 & $\mathrm{Up}^{* *}$ \\
\hline F35H10.4 & vha-5 & $\begin{array}{l}\text { Ortholog of subunit a of the V0 domain of vacuolar } \\
\text { proton-translocating ATPase (V-ATPase) }\end{array}$ & 0.4572 & Up** \\
\hline $\mathrm{C} 46 \mathrm{C} 2.2$ & & $\begin{array}{l}\text { Synaptic vesicle transporter SVOP and related } \\
\text { transporters (major facilitator superfamily) [KOG0255] }\end{array}$ & 0.3887 & Up** \\
\hline T01H3.1 & vha-4 & $\begin{array}{l}\text { Ortholog of subunit c" of the V0 domain of vacuolar } \\
\text { proton-translocating ATPase (V-ATPase) }\end{array}$ & 0.3644 & Up** \\
\hline R10E11.8 & vha-1 & $\begin{array}{l}\text { Ortholog of subunit c of the V0 domain of vacuolar } \\
\text { proton-translocating ATPase (V-ATPase) }\end{array}$ & 0.3339 & Up* \\
\hline F20B6.2 & vha-12 & $\begin{array}{l}\text { Ortholog of subunit B of the V1 domain of vacuolar } \\
\text { proton-translocating ATPase (V-ATPase) }\end{array}$ & 0.1606 & Up** \\
\hline Y49A3A.2 & vha-13 & $\begin{array}{l}\text { Ortholog of subunit A of the V1 domain of vacuolar } \\
\text { proton-translocating ATPase (V-ATPase) }\end{array}$ & 0.1142 & Up* \\
\hline Y32F6A.4 & & Amino acid transporters [KOG1303] & -0.9146 & Down ${ }^{* *}$ \\
\hline \multicolumn{5}{|c|}{ Osmolyte synthesis } \\
\hline $\mathrm{C} 23 \mathrm{H} 3.7$ & tre -5 & Trehalase $\mathrm{a}^{\mathrm{a}}$ & 4.0072 & Up** \\
\hline F47G4.3 & gpdh-1 & Glycerol-3-phosphate dehydrogenase & 1.9865 & $\mathrm{Up}^{* *}$ \\
\hline F19H8.1 & tps-2 & Trehalose-6-phosphate synthase ${ }^{a}$ & 0.7553 & Up** \\
\hline
\end{tabular}

Table 2. DEGs in case of $k g b-1 \Delta_{\text {ho }} / \mathrm{WT}_{\text {ho }}$ (sequence, public gene name, function, $\log _{2}$-fold change, regulatory direction) for membrane transports identified using WormBase ${ }^{\mathrm{a}}$ and/or $\mathrm{KOG}^{\mathrm{b}}$, with asterisks indicating the respective false discovery rate $\left(*:<0.005 ;{ }^{* *}:<0.001\right)$

\begin{tabular}{|c|c|c|c|c|}
\hline Sequence & $\begin{array}{l}\text { Public } \\
\text { name }\end{array}$ & Function & $\begin{array}{c}\log _{2}(\mathrm{kgb}- \\
\left.1 \Delta \Delta_{\mathrm{ho}} / \mathrm{WT}_{\mathrm{ho}}\right)\end{array}$ & Regulation \\
\hline \multicolumn{5}{|c|}{ Membrane transport } \\
\hline C43F9.6 & $n k b \cdot 2$ & $\mathrm{Na}^{+} / \mathrm{K}^{+}-\mathrm{ATPase}$, beta subunit ${ }^{\mathrm{a}}$ & 3.3518 & Up** \\
\hline Y46G5A.30 & snf -5 & Sodium-neurotransmitter symporter familya & 2.9701 & Up** \\
\hline C01G12.8 & catp-4 & $\begin{array}{l}\text { Cation transporting ATPase }{ }^{a} ; \mathrm{Na}^{*} / \mathrm{K}^{+}-\text {ATPase, alpha } \\
\text { subunit [KOG0203] }\end{array}$ & 1.9698 & Up** \\
\hline Y51A2D.4 & hmit-1.1 & $\mathrm{H}^{+}$-dependent myo-inositol transporter & 1.3486 & Up* \\
\hline Y43F4B.7 & & Amino acid transporter [KOG1304] ${ }^{\mathrm{b}}$ & 0.478 & Up** \\
\hline M02F 4.8 & aqp $\cdot 7$ & Aquaglyceroporina & 0.2659 & Up** \\
\hline F52E1.10 & vha-18 & $\begin{array}{l}\text { Ortholog of subunit } \mathrm{H} \text { of the } \mathrm{V} 1 \text { domain of vacuolar } \\
\text { proton-translocating ATPase (V-ATPase) }\end{array}$ & 0.2596 & $\mathrm{Up}^{*}$ \\
\hline VW02B12L.1 & vha-6 & $\begin{array}{l}\text { Ortholog of subunit a of the V0 domain of vacuolar } \\
\text { proton-translocating ATPase (V-ATPase) }\end{array}$ & 0.2084 & Up** \\
\hline B0365.3 & eat-6 & Ortholog of the alpha subunit of a Na+/K+-ATPase $\mathrm{K}^{a}$ & 0.0817 & Up** \\
\hline F20B6.2 & vha-12 & $\begin{array}{l}\text { Ortholog of subunit B of the V1 domain of vacuolar } \\
\text { proton-translocating ATPase (V-ATPase) }\end{array}$ & -0.1884 & Down** \\
\hline
\end{tabular}

DEGs for membrane transports and osmolyte syntheses

Supported by 'Transport DB' [38], we then analyzed the transcriptome data for potentially stress-relevant DEGs coding for membrane transporters. This search revealed twelve DEGs (eleven of them up-regulated) in case of $\mathrm{WT}_{\mathrm{ho}} / \mathrm{WT}_{\text {ctrl }}$ (Table 1) and ten DEGs (nine up-regulated) for $\mathrm{kgb}-1 \Delta_{\mathrm{ho}} / \mathrm{WT}_{\mathrm{ho}}$ (Table 2). The two gene groups included three DEGs for members of the major facilitator family, one DEG for a glutamate transporter, and five DEGs for subunits of the V-ATPase, which particularly energizes apical membranes $\left(\mathrm{WT}_{\mathrm{ho}} /\right.$ $\mathrm{WT}_{\text {ctrl }} \mathrm{I}$ as well as DEGs for one sodium-neurotransmitter symporter, one $\mathrm{H}^{+}$-dependent myo-inositol transporter, one aquaglyceroporin, and three DEGs each for V-ATPase subunits and subunits of the $\mathrm{Na}^{+} / \mathrm{K}^{+}$-ATPase, which energizes baso-lateral membranes $\left(\mathrm{kg} b-1 \Delta_{\mathrm{ho}} / \mathrm{WT}_{\mathrm{ho}}\right)$. In case of $\mathrm{WT}_{\mathrm{ho}} / \mathrm{WT}_{\mathrm{ctrl}}$, DEGs for enzymes involved in osmolyte synthesis were found in addition (Table 1). 

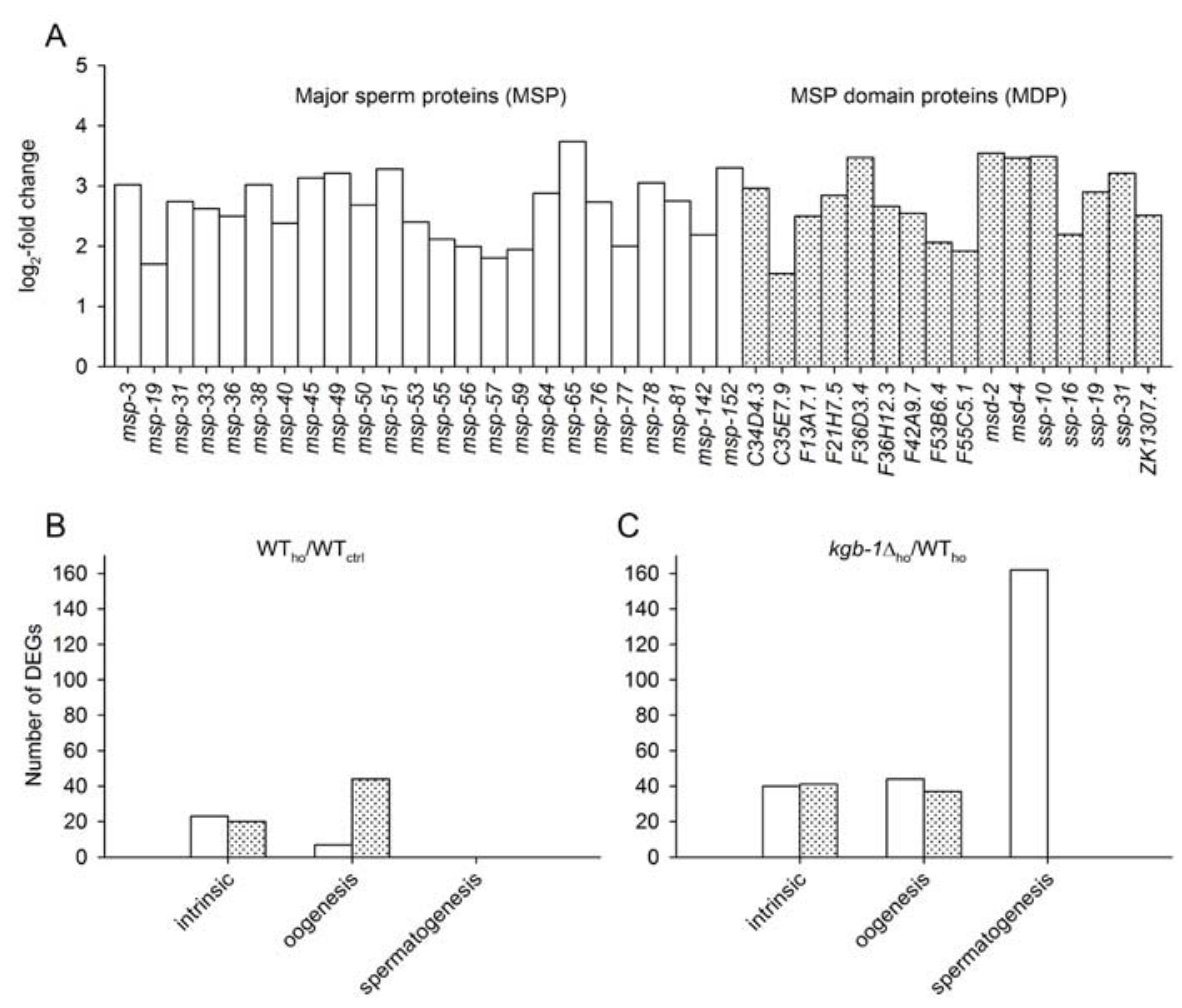

Fig. 12. DEGs identified as germline-enriched genes in case of $\mathrm{WT}_{\mathrm{ho}} / \mathrm{WT}_{\mathrm{ctrl}}$ and $k g b-1 \Delta_{\mathrm{ho}} / \mathrm{WT}_{\mathrm{ho}}$ ( $(\mathrm{A})$ In case of $\mathrm{kgb}-1 \Delta_{\mathrm{ho}} / \mathrm{WT}_{\mathrm{ho}}$, highly up-regulated genes for major sperm proteins (MSPs) and MSP domain proteins (MDPs; dotted bars) were detected. Identity to 'germline-enriched' genes [45] was found to be lower in case of (B) $\mathrm{WT}_{\text {ho }} / \mathrm{WT}_{\text {ctrl }}$ than (C) $\mathrm{kgb}-1 \Delta_{\text {ho }} / \mathrm{WT}_{\text {ho }}$ (94 vs $324 \mathrm{DEGs),} \mathrm{with} \mathrm{the} \mathrm{latter} \mathrm{contrast} \mathrm{including} 162$ upregulated (white bars) and no down-regulated (dotted bars) 'spermatogenesis-enriched' genes.

\section{DEGs identified as DAF-16 target genes}

To check for DAF-16 target gene expressions, the $\mathrm{WT}_{\mathrm{ho}} / \mathrm{WT}_{\text {ctrl }}$ and $k g b-1 \Delta_{\mathrm{ho}} / \mathrm{WT}_{\mathrm{ho}}$ data were analyzed with respect to 486 identified DAF-16 target genes [44] resulting in $46\left(\mathrm{WT}_{\mathrm{ho}} / \mathrm{WT}_{\text {ctrl }}\right)$ or $66\left(\mathrm{kgb}-1 \Delta_{\mathrm{ho}} / \mathrm{WT}_{\mathrm{ho}}\right)$ hits. For $\mathrm{WT}_{\mathrm{ho}} / \mathrm{WT}_{\text {ctrr }}$, the more highly upregulated DEGs ( $\log _{2}$-fold changes $\geq 1$ ) included one DEG for a small heat shock protein (hsp-12.6) and three DEGs for cytochrome P450s (cyp-35C1, cyp-35A2, cyp$35 \mathrm{~A} 3$ ) as well as two yet not functionally described genes (dod-3, F13H6.3). In case of $k g b-1 \Delta_{\text {ho }} / \mathrm{WT}_{\mathrm{ho}}$, the more highly up-regulated DEGs coded for one MSP (msp-31), one ShKlike toxin peptide (T24B8.5), one C-type lectin (clec-52), and eight yet not functionally described gene products (C50F7.5, F35E12.5, T24E12.5, T02B5.1, T16G12.4, C05B5.2, F08G5.6, Y32H12A.8). No specific differences in up- and down-regulations were found for the twenty DAF-16 target genes identical in $\mathrm{WT}_{\mathrm{ho}} / \mathrm{WT}_{\mathrm{ctrl}}$ and $k g b-1 \Delta_{\mathrm{ho}} / \mathrm{WT}_{\mathrm{ho}}$.

\section{DEGs identified as germline-enriched genes}

The $k g b-1 \Delta_{\text {ho }} / \mathrm{WT}_{\mathrm{ho}}$ transcriptome data contained many highly up-regulated DEGs for the spermatocyte-specific major sperm proteins (MSP) and MSP domain proteins (MDPs) (Fig. $12 \mathrm{~A}$ ). With respect to all up-regulated DEGs from $\mathrm{kg} b-1 \Delta_{\mathrm{ho}} / \mathrm{WT}_{\mathrm{ho}}$, the GES was indeed highest (9.0) for a cluster consisting of genes for 23 MSPs, 7 MDPs and only seven other proteins. Consequently, we analysed the $\mathrm{WT}_{\mathrm{ho}} / \mathrm{WT}_{\text {ctrl }}$ and $k g b-1 \Delta_{\text {ho }} / \mathrm{WT}_{\text {ho }}$ data with respect to 3143 germline-enriched genes [45], which had been subclassified into 1248 intrinsic genes (i.e., involved in mitotic proliferation and early meiosis I in the distal germline), 1030 oogenesis- 


\section{Cellular Physiology and Biochemistry}

Cell Physiol Biochem 2014;34:1951-1973

\begin{tabular}{l|l}
\hline DOI: $10.1159 / 000366392$ & (c) 2014 S. Karger AG, Basel
\end{tabular}

Published online: November 25, 2014 www.karger.com/cpb

Gerke et al.: The JNK-Like MAPK KGB-1 of C. Elegans

enriched genes (i.e., increased expression in hermaphrodites producing only oocytes), and 865 spermatogenesis-enriched genes (i.e., increased expression in hermaphrodites producing only sperm), with a possible overlap between intrinsic and oogenesis-enriched genes. 94 DEGs in case of $\mathrm{WT}_{\mathrm{ho}} / \mathrm{WT}_{\text {ctrl }}$ (Fig. 12B) and $324 \mathrm{DEGs}$ for $k g b-1 \Delta_{\mathrm{ho}} / \mathrm{WT}_{\mathrm{ho}}$ (Fig. 12C) were identical to germline-enriched genes. Particularly striking was the high identity $(18.7 \%)$ with spermatogenesis-enriched genes in case of $\mathrm{kgb}-1 \Delta_{\mathrm{ho}} / \mathrm{WT}_{\mathrm{ho}}$ (162 up-regulated DEGs; Fig. 12C). Further specific investigation of the transcriptome data revealed fog-1 (isoform b) and fog-3, whose protein products promote sperm fate specification [46, 47], as highly up-regulated DEGs ( $\log _{2}$-fold changes: 2.47 and 3.74) in case of $k g b-1 \Delta_{\text {ho }} / \mathrm{WT}_{\text {ho }}$. The germline RNA helicase genes glh-1 and glh-4 were also up-regulated DEGs ( $\log _{2}$-fold changes: 0.25 and 0.24$)$ in case of $k g b-1 \Delta_{\text {ho }} / \mathrm{WT}_{\mathrm{ho}}$. Thus, $k g b-1$ mutation $\left(k g b-1 \Delta_{\mathrm{ho}} / \mathrm{WT}_{\mathrm{ho}}\right)$ promotes spermatogenesis.

\section{Discussion}

Moderate hyperosmolarity did not significantly alter reproduction rate and lifespan in $k g b-1 \Delta$ (Fig. 2), and $k g b-1$ mutation/RNAi clearly promoted the tolerance to severe hyperosmolarity (Fig. 3, 4). In agreement with a previous study [29], KGB-1 activity (in WT) reduced the stress resistance of the (young) adult worms used in our study. Expression of gpdh-1 and GPDH activity, which serve as standard osmoprotection the synthesis of glycerol [3], were however higher in WT than in $k g b-1 \Delta$ (Table 1; Fig. 5). In line with the downstream control of AP-1 genes (jun, fos; Fig. 6) and elements [25, 28] by KGB-1, fos-1 $\Delta$ /-RNAi promoted hyperosmotic tolerance even more than $\mathrm{kg} b$-1 $\Delta /$-RNAi (Fig. 7). The low reproduction rate and shortened lifespan of $\mathrm{kgb}-1 \Delta$ (Fig. 2) went hand in hand with a reduced expression of genes for protein biosynthesis (Fig. 9B, 11). Genes for spermatogenesis, however, were highly upregulated in $\mathrm{kgb}-1 \Delta$ (Fig. 12). Thus, KGB-1 (in WT) evidently promotes reproduction, lifespan, and protein biosynthesis and also ensures balanced gametogenesis but affects hyperosmotic tolerance negatively, even though a standard osmoprotection (glycerol accumulation) was more active when KGB-1 was operative. These basic facts will now be examined in detail.

\section{KGB-1, protein biosynthesis and chaperones, reproduction and lifespan}

KGB-1 promotes reproduction and lifespan in WT (Fig. 2) (see also [28, 29]). Genes for translation, ribosomal structure and biogenesis (KOG category [J]) were severely down-regulated in case of $\mathrm{kgb}-1 \Delta_{\mathrm{ho}} / \mathrm{WT}_{\mathrm{ho}}$ (Fig. 9b) and predominantly up-regulated in case of $\mathrm{WT}_{\mathrm{ho}} / \mathrm{WT}_{\text {ctrl }}$ (Fig. 9a). It can therefore be concluded that the down-regulation of $R P$ and Ribi genes (Fig. 11) was due to $\mathrm{kgb}-1$ mutation and not hyperosmolarity. Reduced translation rates (down-regulated $R P$ and Ribi genes) could impair reproduction and may also shorten lifespan, when developmental disorders occur due to inadequate protein provision. The advantage of a lowered protein biosynthesis rate would be a reduced risk of overloading the chaperone machinery and producing misfolded proteins under stress [6], which could be a key mechanism for the enhanced hyperosmotic tolerance of $k g b-1 \Delta$ (see below). Actually, gpdh-1 expression, GPDH activity, and glycerol accumulation have been shown to be promoted by disturbed protein homeostasis and enhanced protein damage $[1,3]$. As this may happen more easily in WT, the up-regulated gpdh-1 expression and GPDH activity in this strain (Table 1; Fig. 5) may result from an overstressed chaperone machinery. The down-regulation of seventeen DEGs for chaperones and eleven DEGs for enzymes involved in ubiquitination/proteasomal degradation in case of $\mathrm{kgb}-1 \Delta_{\mathrm{ho}} / \mathrm{WT}_{\mathrm{ho}}$ (see Results section) would also fit in the scenario of an under-utilized chaperone machinery in $\mathrm{kgb}-1 \Delta$ and less protein damage in $\mathrm{kgb}-1 \Delta$ than in WT at severe hyperosmotic stress (see below). The opposite effect of a KGB-1-mediated activation of the ubiquitin proteasome system has been reported by [28].

$R P$ and Ribigenes are tightly co-regulated genes in response to varying cellular conditions $[43,48,49]$, and $R P$ genes have shared promoter motifs also in $C$. elegans [50]. Ribosome 


\section{Cellular Physiology and Biochemistry}

Cell Physiol Biochem 2014;34:1951-1973

\begin{tabular}{l|l}
\hline DOI: $10.1159 / 000366392$ & (C) 2014 S. Karger AG, Basel
\end{tabular}

Gerke et al: The JNK-Like MAPK KGB-1 of C. Elegans

biogenesis, translation, transcription, metabolism, and autophagy are controlled by the TOR pathway [51, 52], with a TORC1 substrate (Sch9 kinase; [53]) functioning as master regulator of ribosome biogenesis [54]. JNK activates mTORC1 signaling by phosphorylation of the mTORC1 protein Raptor [55]. As JNK-1 and JKK-1 (the associated MAP2K) are expressed in $C$. elegans only in neurons $[9,10]$, whereas the JNK-like MAPK KGB-1 is expressed ubiquitously including non-neuronal cells (Fig. 1) (see also [28]), it is possible that KGB-1 promotes the expression of $R P$ and Ribi genes via the TOR pathway.

Already known KGB-1 functions are interactions with germline RNA helicases (GLHs), which are constitutive elements of germline-specific $P$ granules (i.e., germline determinants) $[19,56] . \mathrm{kg} b-1 \Delta$ was reported to show a strongly up-regulated GLH-1 level and disorganized GLH-1 locations in germ cells [16]. It was also suggested that KGB-1 and CSN-5 control germline homeostasis, with KGB-1 targeting GLH-1 for proteasomal degradation. Germline RNA helicase genes (glh-1, glh-4; see Results section), spermatogenesis-enriched genes, and genes for the spermatocyte-specific MSPs and MDPs [57], which are dominant sperm proteins [58] that enable sperm motility [59] and affect as hormones female germ cells [60], were up-regulated in $k g b-1 \Delta\left(k g b-1 \Delta_{\mathrm{ho}} / \mathrm{WT}_{\mathrm{ho}}\right)$ but not in $\mathrm{WT}\left(\mathrm{WT}_{\mathrm{ho}} / \mathrm{WT}_{\mathrm{ctrr}}\right.$ ) (Fig. 12). The germline-specific genes fog-1 and $f o g-3^{\text {ho }}$ (feminization of germline; [61]) but not tra-1, whose protein product (TRA-1A) exercises transcriptional control over fog-3 [62] and likely fog-1 [63], were also highly up-regulated in $\mathrm{kgb}-1 \Delta$ (see Results section). FOG-1 and FOG-3 promote sperm fate specification [46, 47], and the phosphorylation state of FOG-3 regulates the initiation (unphosphorylated FOG-3) and maintenance (phosphorylated FOG-3) of the sperm fate program [61]. The specific kinases, which affect the phosphorylation state of FOG-3, are yet not known. In case KGB-1 would be such a FOG3 phosphorylating kinase, the sperm fate program might be initiated in $\mathrm{kgb}-1 \Delta$. Anyhow, the up-regulation of $f \circ g-1$ and $f o g-3$ definitely fits to the shift to spermatogenesis in $\mathrm{kg} b-1 \Delta$. A previous study already reported a temperature-sensitive $\left(>25^{\circ} \mathrm{C}\right)$, sterile phenotype of $k g b-1 \Delta$ [19]. The sterile $k g b-1 \Delta$ worms produced sperm during the L4 stage but no functional oocytes. Thus, the reduced reproduction rate (Fig. 2) as well as the switch to spermatogenesis (Fig. 12) in $\mathrm{kgb}-1 \Delta$ at $20^{\circ} \mathrm{C}$ may be linked to a pre-stage of the sterile phenotype of $\mathrm{kgb}-1 \Delta$ at $25^{\circ} \mathrm{C}$, even if negative effects of a reduced protein biosynthesis rate on the reproduction rate of the mutant would be considered in addition (see above).

\section{Relationships between KGB-1, Jun-1 and Fos-1}

Jun and Fos are elements of the activator protein 1 (AP-1) early response transcription factor [41]. The MAPK JNK activates c-Jun, which typically causes $c$-jun expression via binding of c-Jun:c-Fos, for example, to CRE-binding sites in the $c$-jun promoter. JNK additionally promotes $c$-fos expression by activating the transcription factor Elk-1, which can bind to ETS-binding sites in the regulatory region of $c$-fos [40]. Thus, Jun and Fos genes are potential downstream targets of the JNK-like MAPK KGB-1, which is supported by the existence of CREbinding sites in the promoters of jun-1c and particularly jun-1d and ETS-binding sites in the regulatory regions of $f o s-1 a$ and $f o s-1 b$ from $C$. elegans (R. J. Paul, unpublished data). Previous studies already reported KGB-1-dependent jun-1 expression [27] and JNK-1-mediated phosphorylation of c-Elk1 [64] in C. elegans. Another study showed fos-1a expression to be restricted to the somatic gonad, but fos-1b expression to occur in many cells and tissues of $C$. elegans [30]. This study showed positive effects of moderate hyperosmolarity $(200 \mathrm{mmol} / \mathrm{L}$ $\mathrm{NaCl})$ and negative effects of severe hyperosmolarity (400 mmol/L NaCl) on $\mathrm{kgb}-1$, jun$1 a-e$, and fos-1ab transcription and $P_{\text {fos }-1}$-dependent ECFP expression (Fig. 6A, B, D, F). The significantly (or noticeably) lower expression of jun-1a-e (or fos-1ab) in $\mathrm{kg} b$-1 $1 \Delta$ than in WT at moderate hyperosmolarity shows that KGB-1 affects jun-1a-e (and likely fos-1ab) expression positively (Fig. 6B-E). The even higher hyperosmotic tolerance of C. elegans after fos-1-RNAi treatment in comparison to $\mathrm{kg} b$-1-RNAi (Fig. 7A, C) is also in line with a downward control of $f o s-1$ expression and/or FOS- 1 activation $[25,28]$ by KGB-1.

The dependence of $k g b-1$, jun-1, and fos-1 expression on salt concentration in WT (Fig. $6 \mathrm{~A}, \mathrm{~B}, \mathrm{D}, \mathrm{F}$ ) implies a reciprocal relationship between the KGB-1/AP-1 signaling system and 


\section{Cellular Physiology and Biochemistry}

Cell Physiol Biochem 2014;34:1951-1973

\begin{tabular}{l|l}
\hline DOI: $10.1159 / 000366392$ & (c) 2014 S. Karger AG, Basel
\end{tabular}

Published onIIne: November 25, 2014 www.karger.com/cpb

Gerke et al.: The JNK-Like MAPK KGB-1 of C. Elegans

hyperosmolarity, with its absence or weakness in $\mathrm{kg} b-1 \Delta$ (Fig. 6C, E) indicating that this relationship is established via KGB-1. Considering in addition the positive effects of KGB-1 on protein biosyntheses (Fig. 9B, 11), a possible stress tolerance mechanism emerges based on the reciprocal relationship between stress intensity and the KGB-1/AP-1 signaling system together with positive effects of KGB-1/AP-1 signaling on protein biosyntheses: moderate hyperosmolarity should promote protein biosyntheses via enhanced KGB-1/AP-1 signaling, which will probably also lead to an enlargement of the chaperone machinery (see [12] for KGB-1 impacts on ER stress management), whereas severe hyperosmolarity likely impairs protein biosyntheses via inhibited KGB-1/AP-1 signaling resulting in an easing the burden of the existing chaperone machinery not expandable under stress. Under all conditions, the balance between protein synthesis rate and the existing stock of chaperones must be maintained. In this framework, $\mathrm{kgh}-1$ mutation would impede the signal flow between stressor (hyperosmolarity) and the downward signaling system (AP-1; Fig. 6C, E), but enhance stress tolerance in this way by the resulting decrease in protein biosynthesis rate, which should lower the risk of overloading the existing chaperone machinery. Likewise, a recent paper has concluded that inhibition of protein translation protects extant proteins from damage brought about by an environmental stressor' [6].

\section{Hyperosmotic tolerance mechanisms in WT}

To intensify compatible osmolyte (glycerol) production, gpdh-1 expression and GPDH activity were up-regulated in WT (Table 1; Fig. 5). Concerning another compatible osmolyte (trehalose), the elevated expression of tre-5 (trehalase) and tps-2 (trehalose-6-phosphate synthase 2) is however ambiguous. Whereas trehalase degrades trehalose to glucose, TPS1 and TPS2 activities (also referred to as trehalose-phosphatase, TPP; [65]) serve the production of trehalose from glucose-6-phosphate and UDP-glucose [66], with tps-2 (TPS2) expression apparently more important for the hyperosmotic tolerance of $C$. elegans [4]. The much higher up-regulation of tre-5 in comparison to tps-2 indicates a shift from trehalose synthesis to trehalose degradation possibly to support glycolytic energy production during the acute and severe hyperosmotic stress $(400 \mathrm{mmol} / \mathrm{L} \mathrm{NaCl})$ applied in the transcriptome study. Aside from syntheses, osmolyte imports (possibly energized by apical V-ATPases) by members of the major facilitator family, which transport a wide range of substrates (e.g., ions, sugars, amino acids; [67]), and/or a transporter (vglu-2) for the import of glutamate as compatible osmolyte [68] may contribute to the hyperosmotic tolerance of WT (Table 1).

Further genes up-regulated in WT under hyperosmotic conditions included genes for type IV and XIII collagens (Fig. 10A). The collagen genes mostly code for components of the cuticular exoskeleton [69], with their up-regulation possibly reducing the cuticle's water permeability. Two other up-regulated collagen genes (emb-9, let-2) code for components of the tissue-surrounding basement membranes [70]. Mutations in two of the up-regulated genes (dpy-2, dpy-7) or in another set of genes (e.g., osr-1, osm-7, osm-11), whose products are likely secreted from the hypodermis, affect the osmotic resistance of $C$. elegans positively $[71,72]$, which was explained by intensified glycerol synthesis due to specific cuticle defects (dpy mutants) or constitutive osmotic stress signaling (e.g., osr and osm mutants). UDPglucuronosyl/-glucosyl transferases are involved in the export of toxic or reactive compounds [73], with their up-regulation (Fig. 10B) indicating peroxidized lipids and/or other cellular damage in WT at severe hyperosmolarity.

\section{Hyperosmotic tolerance mechanisms in $\mathrm{kgb}-1 \Delta$}

Acute and severe hyperosmolarity resulted in transhypodermal water loss, reduced body volume, and severely restricted motility (Fig. 4), with the latter likely due to a decrease in turgor pressure and a weakening of the hydroskeleton. The faster recovery of $k g b-1 \Delta$ in comparison to WT points to differences between both strains in the presence or strength of an immediately effective restore mechanism. It also implies a reduced risk of cell damage by molecular crowding [74] and elevated cellular ionic strength [1] in $\mathrm{kgb}-1 \Delta$, which likely also contributed to its higher hyperosmotic tolerance. Regulatory volume increase (RVI; 


\section{Cellular Physiology and Biochemistry}

Cell Physiol Biochem 2014;34:1951-1973

\begin{tabular}{l|l}
\hline DOI: $10.1159 / 000366392$ & (c) 2014 S. Karger AG, Basel
\end{tabular}

Published onIIne: November 25, 2014 www.karger.com/cpb

Gerke et al.: The JNK-Like MAPK KGB-1 of C. Elegans

[75]) is a good candidate for an immediately effective restore mechanism, which is based on the net import of inorganic ions to promote water reflux and cell volume recovery, and the subsequent exchange of inorganic ions against compatible osmolytes (e.g., glycerol, trehalose) that do not interfere with cell functions [4]. The distinct up-regulation of genes for membrane transporters in $k g b-1 \Delta$, which included genes for $\mathrm{Na}^{+} / \mathrm{K}^{+}$-ATPase $\alpha / \beta$ subunits, aquaglyceroporin, a myo-inositol transporter, and a sodium-neurotransmitter symporter (snf-5) (Table 2), indicates a particular significance of RVI in this strain. The upregulation also implies negative effects of KGB-1 (in WT) on gene expressions for membrane transporters, perhaps to reduce energy-consuming membrane transports under non-stress conditions. A previous study on transcriptional responses to acute hyperosmolarity [76] actually classified genes for $\beta 1-\mathrm{Na}^{+} / \mathrm{K}^{+}$-ATPase and a sodium/myo-inositol transporter (SMIT) as early genes and that for aldose reductase (AR), which catalyzes synthesis of the compatible osmolyte sorbitol, as late gene. Other studies also showed an up-regulation of $\mathrm{Na}^{+}-\mathrm{K}^{+}$-ATPase $\alpha / \beta$-subunits (mRNA, protein) at severe hyperosmolarity $[77,78]$. As key element for the energization of membrane transports, a higher number of expressed $\mathrm{Na}^{+} / \mathrm{K}^{+}-$ ATPases supports the import of inorganic ions/water and compatible osmolytes, resulting in an accelerated water uptake, a faster recovery of the hydroskeleton, and a shorter period of molecular crowding and elevated ionic strength. Up-regulated aquaglyceroporins ( $a q p-7$; [79]) promote water and glycerol imports, and the up-regulated $\mathrm{H}^{+}$-dependent myo-inositol transporter (hmit-1.1) possibly uses the transmembranous proton gradient provided by V-ATPases for imports of myo-inositol (i.e., another compatible osmolyte). Actually, the hyperosmotic up-regulation of hmit-1.1 as well as osmoprotection by intestinal HMIT-1.1 have already been shown in C. elegans [5]. The highly up-regulated snf-5 has $31 \%$ identity to human glyt1 (slc6a9), which codes for a transport protein (mammalian $\mathrm{Na}^{+}$- and $\mathrm{Cl}^{-}-$ dependent glycine neurotransmitter transporter, GLYT1) involved in cell volume control and osmoprotection [80].

Hyperosmotic tolerance and the DAF-2 pathway

daf-2 mutation (resulting in a higher nuclear DAF-16 level) or the overexpression of DAF-16 in TJ356 [24, 44] improved (Fig. 8B) but daf-16-RNAi reduced (Fig. 8C) the hyperosmotic tolerance of $C$. elegans. Moreover, the hyperosmotic range was similar for nuclear DAF-16::GFP localization and the survival advantage of TJ356 in comparison to WT (Fig. 8B). Thus, the translocation of DAF-16 into cell nuclei and subsequent DAF-16 target gene expressions promote the tolerance to severe hyperosmolarity. A previous study already reported a DAF-16-mediated increase in hyperosmotic tolerance [4], which was related, inter alia, to genes for enzymes involved in trehalose synthesis (tps-1, tps-2; see above). However, nuclear DAF-16::GFP translocations were not detected due to the moderate stress applied in the previous study $(200 \mathrm{mmol} / \mathrm{L} \mathrm{NaCl})$. Checking for DAF-16 target genes [44] revealed only one small heat shock protein (hsp-12.6) and three genes for cytochrome P450s, which may be involved in the solubilization of toxic compounds [73], as highly up-regulated DEGs in case of $\mathrm{WT}_{\mathrm{ho}} / \mathrm{WT}_{\text {ctrl }}$. However, the incubation time for RNA-Seq (3 hours) was possibly too short to detect more up-regulated DAF-16 target genes as nuclear DAF-16 translocation was measured only after 24 hours of hyperosmotic incubation. In case of $k g b-1 \Delta_{\mathrm{ho}} / \mathrm{WT}_{\mathrm{ho}}$, the elevated hyperosmotic tolerance of $\mathrm{kgb}-1 \Delta$ may additionally have lowered the demand for up-regulated DAF-16-mediated stress genes.

\section{Conclusions}

This study provided evidence for positive effects of KGB-1 on reproduction, lifespan, protein biosynthesis (RP and Ribi genes), and balanced gametogenesis, which seem to be affected, at least partly, by the KGB-1/AP-1 signaling line. KGB-1 mutation/RNAi enhanced the tolerance of $C$. elegans to hyperosmotic stress. The reciprocal relationship between stress intensity and KGB-1/AP-1 signaling and the positive relationship between KGB-1 signaling 


\section{Cellular Physiology and Biochemistry}

Cell Physiol Biochem 2014;34:1951-1973

\begin{tabular}{l|l}
\hline DOI: $10.1159 / 000366392$ & (C) 2014 S. Karger AG, Basel
\end{tabular}

Published onlıne: November 25, $2014 \quad$ www.karger.com/cpb

Gerke et al.: The JNK-Like MAPK KGB-1 of C. Elegans

and protein biosynthesis indicates a stress tolerance mechanism aiming at the maintained balance between protein syntheses and the stock of chaperones: moderate stress promotes protein syntheses including those for chaperones, whereas severe stress relieves the existing chaperone machinery by depressing protein syntheses. Thus, KGB-1 mutation/RNAi likely enhances hyperosmotic tolerance by a reduced protein biosynthesis rate together with derepressed gene expressions for membrane transporters, which may serve in WT for energy saving purposes. DAF-16 target gene expressions were found to contribute to hyperosmotic tolerance in addition but specific interactions with KGB-1 were not detected.

\section{Acknowledgements}

We thank Natalja Damatova, Frank Nunes, Elena Baraban, and Ulrike Gigengack for supporting measurements and data sets, the Caenorhabditis Genetics Center for providing C. elegans strains, and the Deutsche Forschungsgemeinschaft for financial support (Pa 308/13-1).

\section{Disclosure Statement}

The authors declare that they have no conflict of interest.

\section{References}

1 Strange K: Revisiting the Krogh Principle in the post-genome era: Caenorhabditis elegans as a model system for integrative physiology research. J Exp Biol 2007;210:1622-1631.

$\longrightarrow 2$ Burkewitz K, Choe K, Strange K: Hypertonic stress induces rapid and widespread protein damage in $C$. elegans. Am J Physiol Cell Physiol 2011;301:C566-C576.

- Lamitina T, Huang CG, Strange K: Genome-wide RNAi screening identifies protein damage as a regulator of osmoprotective gene expression. Proc Nat Acad Sci USA 2006;103:12173-12178.

4 Lamitina ST, Strange K: Transcriptional targets of DAF-16 insulin signaling pathway protect C. elegans from extreme hypertonic stress. Am J Physiol Cell Physiol 2005;288:467-474.

-5 Kage-Nakadaia E, Ueharaa T, Mitani S: H+/myo-inositol transporter genes, hmit-1.1 and hmit-1.2, have roles in the osmoprotective response in Caenorhabditis elegans. Biochem Biophys Res Commun 2011;410:471477.

6 Burkewitz K, Choe KP, Choung-Hee Lee E, Deonarine A, Strange K: Characterization of the proteostasis roles of glycerol accumulation, protein degradation and protein synthesis during osmotic stress in C. elegans. PLoS ONE 2012;7:e34153. DOI: 10.1371/journal.pone.0034153.

7 Kültz D: Evolution of osmosensory MAP kinase signaling pathways. Am Zool 2001;41:743-757.

8 Kyriakis JM, Avruch J: Mammalian mitogen-activated protein kinase signal transduction pathways activated by stress and inflammation. Physiol Rev 2001;81:807-869.

-9 Sakaguchi A, Matsumoto K, Hisamoto N: Roles of MAP kinase cascades in Caenorhabditis elegans. J Biochem 2004;136:7-11.

10 Wolf M, Nunes F, Henkel A, Heinick A, Paul RJ: The MAP kinase JNK-1 of Caenorhabditis elegans: Location, activation, and influences over temperature-dependent insulin-like signaling, stress responses, and fitness. J Cell Physiol 2008;214:721-729.

11 Mizuno T, Hisamoto N, Terada T, Kondo T, Adachi M, Nishida E, Kim DH, Ausubel FM, Matsumoto K: The Caenorhabditis elegans MAPK phosphatase VHP-1 mediates a novel JNK-like signaling pathway in stress response. EMBO J 2004;23:2226-2234.

12 Mizuno T, Fujiki K, Sasakawa A, Hisamoto N, Matsumoto K: Role of the Caenorhabditis elegans Shc adaptor protein in the c-Jun N-terminal kinase signaling pathway. Mol Cell Biol 2008;28:7041-7049.

13 Fujiki K, Mizuno T, Hisamoto N, Matsumoto K: The Caenorhabditis elegans Ste20-related kinase and Ractype small GTPase regulate the c-Jun N-terminal kinase signaling pathway mediating the stress response. Mol Cell Biol 2010;30:995-1003. 


\section{Cellular Physiology and Biochemistry}

Cell Physiol Biochem 2014;34:1951-1973

\begin{tabular}{l|l}
\hline DOI: $10.1159 / 000366392$ & (C) 2014 S. Karger AG, Basel
\end{tabular}

Published online: November 25, $2014 \quad$ www.karger.com/cpb

Gerke et al.: The JNK-Like MAPK KGB-1 of C. Elegans

14 Kim DH, Liberati NT, Mizuno T, Inoue H, Hisamoto N, Matsumoto K, Ausubel FM: Integration of Caenorhabditis elegans MAPK pathways mediating immunity and stress resistance by MEK-1 MAPK kinase and VHP-1 MAPK phosphatase. Proc Nat Acad Sci USA 2004;101:10990-10994.

15 Kim DH, Feinbaum R, Alloing G, Emerson FE, Garsin DA, Inoue H, Tanaka-Hino M, Hisamoto N, Matsumoto K, Tan M-W, Ausubel FM: A conserved p38 MAP kinase pathway in Caenorhabditis elegans innate immunity. Science 2002;297:623-626.

-16 Orsborn AM, Li W, McEwen TJ, Mizuno T, Kuzmin E, Matsumoto K, Bennett KL: GLH-1, the C.elegans P granule protein, is controlled by the JNK KGB-1 and by the COP9 subunit CSN-5. Development 2007;134:3383-3392.

17 Koga M, Zwaal R, Guan KL, Avery L, Ohshima Y: A Caenorhabditis elegans MAP kinase kinase, MEK-1, is involved in stress responses. EMBO J 2000;19:5148-5156.

-18 Neumann-Haefelin E, Qi W, Finkbeiner E, Walz G, Baumeister R, Hertweck M: SHC-1/p52Shc targets the insulin/IGF-1 and JNK signaling pathways to modulate life span and stress response in C. elegans. Genes Dev 2008;22:2721-2735.

19 Smith P, Leung-Chiu WM, Montgomery R, Orsborn A, Kuznicki K, Gressman-Coberly E, Mutapcic L, Bennett KL: The GLH proteins, Caenorhabditis elegans P granule components, associate with CSN-5 and KGB-1 proteins, necessary for fertility, and with ZYX-1, a predicted cytoskeletal protein. Dev Biol 2002;251:333347.

20 Kuznicki KA, Smith PA, Leung-Chiu WM, Estevez AO, Scott HC, Bennett KL: Combinatorial RNA interference indicates GLH-4 can compensate for GLH-1; these two P granule components are critical for fertility in $C$. elegans. Development 2000;127:2907-2916.

-21 Spike C, Meyer N, Racen E, Orsborn A, Kirchner J, Kuznicki K, Yee C, Bennett KL, Strome S: Genetic analysis of the Caenorhabditis elegans GLH family of P-Granule proteins. Genetics 2008;178:1973-1987.

-22 Updike D, Strome S: P granule assembly and function in Caenorhabditis elegans germ cells. J Androl 2010;31:53-60.

23 Cope GA, Deshaies RJ: COP9 signalosome: a multifunctional regulator of SCF and other cullin-based ubiquitin ligases. Cell 2003;114:663-671.

-24 Henderson ST, Johnson TE: DAF-16 integrates developmental and environmental inputs to mediate aging in the nematode Caenorhabditis elegans. Curr Biol 2001;11:1975-1980.

25 Hattori A, Mizuno T, Akamatsu M, Hisamoto N, Matsumoto K: The Caenorhabditis elegans JNK signaling pathway activates expression of stress response genes by derepressing the Fos/HDAC repressor complex. PLoS Genet 2013;9:e1003315. DOI: 10.1371/journal.pgen.1003315.

-26 Huffman DL, Abrami L, Sasik R, Corbeil J, van der Goot FG, Aroian RV: Mitogen-activated protein kinase pathways defend against bacterial pore-forming toxins. Proc Nat Acad Sci USA 2004;101:10995-11000.

-27 Kao C-Y, Los FCO, Huffman DL, Wachi S, Kloft N, Husmann M, Karabrahimi V, Schwartz J-L, Bellier A, Ha C, Sagong Y, Fan H, Ghosh P, Hsieh M, Hsu C-S, Chen L, Aroian RV: Global functional analyses of cellular responses to pore-forming toxins. PLoS Pathog 2011;7:e1001314. DOI: 10.1371/journal.ppat.1001314.

28 Uno M, Honjoh S, Matsuda M, Hoshikawa H, Kishimoto S, Yamamoto T, Ebisuya M, Yamamoto T, Matsumoto K, Nishida E: A fasting-responsive signaling pathway that extends life span in C. elegans. Cell Rep 2013;3:79-91.

-29 Twumasi-Boateng K, Wang TW, Tsai L, Lee KH, Salehpour A, Bhat S, Tan MW, Shapira M: An age-dependent reversal in the protective capacities of JNK signaling shortens Caenorhabditis elegans lifespan. Aging Cell 2012;11:659-667.

-30 Sherwood DR, Butler JA, Kramer JM, Sternberg PW: FOS-1 promotes basement-membrane removal during anchor-cell invasion in C. elegans. Cell 2005;121:951-962.

-31 Mello CC, Kramer JM, Stinchcomb D, Ambros V: Efficient gene transfer in C. elegans: extrachromosomal maintenance and integration of transforming sequences. EMBO J 1991;10:3959-3970.

-32 Kramer JM, French RP, Park EC, Johnson JJ: The Caenorhabditis elegans rol-6 gene, which interacts with the sqt-1 collagen gene to determine organismal morphology, encodes a collagen. Mol Cell Biol 1990;10:20812089.

33 Sambrook J, Russel DW: Molecular Cloning: A Laboratory Manual, ed 3. Cold Spring Harbor (NY, USA), CSHL Press, 2001.

-34 Stiernagle T: Maintenance of C. elegans; in The C. elegans Research Community (eds.): WormBook, 2006. DOI/10.1895/wormbook.1.7.1, http://www.wormbook.org. 


\section{Cellular Physiology and Biochemistry}

Cell Physiol Biochem 2014;34:1951-1973

\begin{tabular}{l|l}
\hline DOI: $10.1159 / 000366392$ & (c) 2014 S. Karger AG, Basel
\end{tabular}

Gerke et al.: The JNK-Like MAPK KGB-1 of C. Elegans

-35 Mortazavi A, Williams BA, McCue K, Schaeffer K, Wold B: Mapping and quantifying mammalian transcriptomes by RNA-Seq. Nat Meth 2008;5:621-628.

-36 Audic S, Claverie JM: The significance of digital gene expression profiles. Genome Res 1997;7:986-995.

-37 Hoogewijs D, Houthoofd K, Matthijssens F, Vandesompele J, Vanfleteren JR: Selection and validation of a set of reliable reference genes for quantitative sod gene expression analysis in C. elegans. BMC Mol Biol 2008;9:9. DOI: 10.1186/1471-2199-9-9.

-38 Ren Q, Chen K, Paulsen IT: TransportDB: a comprehensive database resource for cytoplasmic membrane transport systems and outer membrane channels. Nucleic Acids Res 2007;35:D274-D279.

-39 Lamitina ST, Morrison R, Moeckel GW, Strange K: Adaptation of the nematode Caenorhabditis elegans to extreme osmotic stress. Am J Physiol Cell Physiol 2004;286:785-791.

40 Turpaev K: Role of transcription factor AP-1 in integration of cell signaling systems. Mol Biol (Mosk) 2006;40:851-866.

-41 Küper C, Beck FX, Neuhofer W: Osmoadaptation of mammalian Cells - an orchestrated network of protective genes. Curr Genomics 2007;8:209-218.

42 Rohlfing A-K, Miteva Y, Hannenhalli S, Lamitina T: Genetic and physiological activation of osmosensitive gene expression mimics transcriptional signatures of pathogen infection in C. elegans. PLoS ONE 2010;5:e9010. DOI: 10.1371/journal.pone.0009010.

-43 Jorgensen P, Rupeš I, Sharom JR, Schneper L, Broach JR, Tyers M: A dynamic transcriptional network communicates growth potential to ribosome synthesis and critical cell size. Genes Dev 2004;18:24912505.

44 Murphy CT, McCarroll SA, Bargmann CI, Fraser A, Kamath RS, Ahringer J, Li H, Kenyon C: Genes that act downstream of DAF-16 to influence the lifespan of Caenorhabditis elegans. Nature 2003;424:277-284.

45 Reinke V, San Gil I, Ward S, Kazmer K: Genome-wide germline-enriched and sex-biased expression profiles in Caenorhabditis elegans. Development 2004;131:311-323.

-46 Luitjens C, Gallegos M, Kraemer, Kimble J, Wickens M: CPEB proteins control two key steps in spermatogenesis in C. elegans. Genes Dev 2000;14:2596-2609.

47 Chen PJ, Singal A, Kimble J, Ellis RE: A novel member of the tob family of proteins controls sexual fate in Caenorhabditis elegans germ cells. Dev Biol 2000;217:77-90.

48 Wade CH, Umbarger MA, McAlear MA: The budding yeast rRNA and ribosome biosynthesis (RRB) regulon contains over 200 genes. Yeast 2006;23:293-306.

-49 Lempiäinen H, Shore D: Growth control and ribosome biogenesis. Curr Opin Cell Biol 2009;21:855-863.

50 Li X, Zhong S, Wong WH: Reliable prediction of transcription factor binding sites by phylogenetic verification. Proc Nat Acad Sci USA 2005;102:16945-16950.

-51 Wullschleger S, Loewith R, Hall MN: TOR signaling in growth and metabolism. Cell 2006;124:471-484.

52 McCormick MA, Tsai SY, Kennedy BK: TOR and ageing: a complex pathway for a complex process. Philos Trans R Soc Lond B Biol Sci 2011;366:17-27.

-53 Urban J, Soulard A, Huber A, Lippman S, Mukhopadhyay D, Deloche O, Wanke V, Anrather D, Ammerer G, Riezman H, Broach JR, De Virgilio C, Hall MN, Loewith R: Sch9 is a major target of TORC1 in Saccharomyces cerevisiae. Mol Cell 2007;26:663-674.

54 Huber A, French SL, Tekotte H, Yerlikaya S, Stahl M, Perepelkina MP, Tyers M, Rougemont J, Beyer AL, Loewith R: Sch9 regulates ribosome biogenesis via Stb3, Dot6 and Tod6 and the histone deacetylase complex RPD3L. EMBO J 2011;30:3052-3064.

55 Fujishita T, Aoki M, Taketo MM: JNK signaling promotes intestinal tumorigenesis through activation of mTOR complex 1 in Apc $\Delta 716$ mice. Gastroenterology 2011;140:1556-1563.

-56 Strome S, Wood WB: Generation of asymmetry and segregation of germ-line granules in early C. elegans embryos. Cell 1983;35:15-25.

57 Burke DJ, Ward S: Identification of a large multigene family encoding the major sperm protein of Caenorhabditis elegans. J Mol Biol 1983;171:1-29.

-58 Scott AL: Nematode sperm. Parasitol Today 1996;12:425-430.

59 Bottino D, Mogilner A, Roberts T, Murray S, Oster G: How nematode sperm crawl. J Cell Sci 2002;115:367384.

60 Miller MA, Nguyen VQ, Lee MH, Kosinski M, Schedl T, Caprioli RM, Greenstein D: A sperm cytoskeletal protein that signals oocyte meiotic maturation and ovulation. Science 2001;291:2144-2147. 


\section{Cellular Physiology and Biochemistry}

Cell Physiol Biochem 2014;34:1951-1973

\begin{tabular}{l|l}
\hline DOI: $10.1159 / 000366392$ & (C) 2014 S. Karger AG, Basel
\end{tabular}

Gerke et al.: The JNK-Like MAPK KGB-1 of C. Elegans

61 Lee MH, Kim KW, Morgan CT, Morgan DE, Kimble J: Phosphorylation state of a Tob/BTG protein, FOG-3, regulates initiation and maintenance of the Caenorhabditis elegans sperm fate program. Proc Nat Acad Sci USA 2011;108:9125-9130.

62 Chen PJ, Ellis RE: TRA-1A regulates transcription of fog-3, which controls germ cell fate in C. elegans. Development 2000;127:3119-3129.

63 Jin SW, Kimble J, Ellis RE: Regulation of cell fate in Caenorhabditis elegans by a novel cytoplasmic polyadenylation element binding protein. Dev Biol 2001;229:537-553.

64 Villanueva A, Lozano J, Morales A, Lin X, Deng X, Hengartner MO, Kolesnick RN: jkk-1 and mek-1 regulate body movement coordination and response to heavy metals through jnk-1 in Caenorhabditis elegans. EMBO J 2001;20:5114-5128.

65 Avonce N, Mendoza-Vargas A, Morett E, Iturriaga G: Insights on the evolution of trehalose biosynthesis. BMC Evol Biol 2006;6:109. DOI: 10.1186/1471-2148-6-109.

-66 Li L, Ye Y, Pan L, Zhu Y, Zheng S, Lin Y: The induction of trehalose and glycerol in Saccharomyces cerevisiae in response to various stresses. Biochem Biophys Res Commun 2009;387:778-783.

67 Law CJ, Maloney PC, Wang DN: Ins and outs of major facilitator superfamily antiporters. Annu Rev Microbiol 2008;62:289-305.

68 Gouffi K, Blanco C: Is the accumulation of osmoprotectant the unique mechanism involved in bacterial osmoprotection? Int J Food Microbiol 2000;55:171-174.

-69 Page AP, Johnstone IL: The cuticle; in The C. elegans Research Community (eds.): WormBook, 2007. DOI/10.1895/ wormbook.1.138.1, http://www.wormbook.org.

70 Kramer JM: Basement membranes; in The C. elegans Research Community (eds.): WormBook, 2005. DOI/10.1895/ wormbook.1.16.1, http://www.wormbook.org.

-71 Solomon A, Bandhakavi S, Jabbar S, Shah R, Beitel GJ, Morimoto RI: Caenorhabditis elegans OSR-1 regulates behavioral and physiological responses to hyperosmotic environments. Genetics 2004;167:161-170.

72 Wheeler JM, Thomas JH: Identification of a novel gene family involved in osmotic stress response in Caenorhabditis elegans. Genetics 2006;174:1327-1336.

73 Oliveira RP, Porter Abate J, Dilks K, Landis J, Ashraf J, Murphy CT, Blackwell TK: Condition-adapted stress and longevity gene regulation by Caenorhabditis elegans SKN-1/Nrf. Aging Cell 2009;8:524-541.

74 Kültz D: Hyperosmolality triggers oxidative damage in kidney cells. Proc Nat Acad Sci USA 2004;101:91779178.

-75 Waldegger S, Matskevitch J, Busch GL, Lang F: Introduction to cell volume regulatory mechanisms; in Lang F (ed.): Cell Volume Regulation. Contrib Nephrol. Basel, Karger, 1998, vol 123, pp 1-7.

-76 Stears RL, Gullans SR: Transcriptional response to hyperosmotic stress; in Storey KB, Storey J (eds.): Environmental stressors and gene responses. Amsterdam, Elsevier, 2000, pp. 129-139.

-77 Ohtaka A, Muto S, Nemoto J, Kawakami K, Nagano K, Asano Y: Hyperosmolality stimulates Na-K-ATPase gene expression in inner medullary collecting duct cells. Am J Physiol Renal Physiol 1996;270:F728-F738.

78 Capasso JM, Rivard CJ, Berl T: Long-term adaptation of renal cells to hypertonicity: role of MAP kinases and Na-K-ATPase. Am J Physiol Renal Physiol 2001;280:F768-F776.

-79 Huang CG, Lamitina T, Agre P, Strange K: Functional analysis of the aquaporin gene family in Caenorhabditis elegans. Am J Physiol Cell Physiol 2007;292:C1867-C1873.

-80 Steeves CL, Hammer M-A, Walker GB, Rae D, Stewart NA, Baltz JM: The glycine neurotransmitter transporter GLYT1 is an organic osmolyte transporter regulating cell volume in cleavage-stage embryos. Proc Nat Acad Sci USA 2003;100:13982-13987. 